\title{
Mineral dust indirect effects and cloud radiative feedbacks of a simulated idealized nocturnal squall line
}

\author{
R. B. Seigel, S. C. van den Heever, and S. M. Saleeby \\ Department of Atmospheric Science, Colorado State University, 1371 Campus Delivery Drive, Fort Collins, CO 80523, USA
}

Correspondence to: R. B. Seigel (rseigel@atmos.colostate.edu)

Received: 11 October 2012 - Published in Atmos. Chem. Phys. Discuss.: 16 November 2012

Revised: 4 March 2013 - Accepted: 6 April 2013 - Published: 30 April 2013

\begin{abstract}
Mineral dust is arguably the most abundant aerosol species in the world and as such potentially plays a large role in aerosol indirect effects (AIEs). This study assesses and isolates the individual responses in a squall line that arise (1) from radiation, (2) from dust altering the microphysics, as well as (3) from the synergistic effects between (1) and (2). To accomplish these tasks, we use the Regional Atmospheric Modeling System (RAMS) set up as a cloudresolving model (CRM). The CRM contains aerosol and microphysical schemes that allow mineral dust particles to nucleate as cloud drops and ice crystals, replenish upon evaporation and sublimation, be tracked throughout hydrometeor transition, and be scavenged by precipitation and dry sedimentation.

Factor separation is used on four simulations of the squall line in order to isolate the individual roles of radiation (RADIATION), microphysically active dust (DUST MICRO), and the nonlinear interactions of those factors (SYNERGY). Results indicate that RADIATION acts to increase precipitation, intensify the cold pool, and enhance the mesoscale organization of the squall line due to changes in microphysics originating from cloud top cooling. Conversely, DUST MICRO decreases precipitation, weakens the cold pool, and weakens the mesoscale organization of the squall line due to an enhancement of the warm rain process. SYNERGY shows little impact on the squall line, except near the freezing level, where an increase in mesoscale organization takes place. The combined effect of the mineral dust AIE due to both DUST MICRO and SYNERGY is to weaken the squall line.
\end{abstract}

\section{Introduction}

Aerosol can effectively serve as cloud condensation nuclei $(\mathrm{CCN})$, giant cloud condensation nuclei (GCCN), and ice nuclei (IN) such that changes in the concentrations of these nuclei impact the microstructure and hence the radiation budget of clouds and precipitating convection (Twomey, 1977; Albrecht, 1989). This is often referred to as the aerosol indirect effect (AIE) and is one of the largest uncertainties in cloud radiative forcing of the climate system (Forster et al., 2007). Because of this, considerable research efforts have been made to better understand aerosol indirect effects on clouds and precipitation using both observations (e.g., Borys et al., 1998; Ferek et al., 2000; Kaufman and Nakajima, 1993; Heymsfield and McFarquhar, 2001; Rosenfeld, 2000; Andrae et al., 2004; Rosenfeld et al., 2008) and models (e.g., Khain et al., 2005; Seifert and Beheng, 2006; van den Heever et al., 2006, 2011; Lee et al., 2008; Storer et al., 2010; Igel et al., 2013; Morrison, 2012; Storer and van den Heever, 2013). However, results from these studies have indicated that aerosol indirect effects are highly variable, demonstrating the sensitive nature of this problem (Rosenfeld and Feingold, 2003; Tao et al., 2012).

The original AIE theories (Twomey, 1977; Albrecht, 1989) were derived from studies of clouds that were comprised only of liquid water (i.e., warm clouds) - shallow cumulus and stratocumulus. These AIEs have been shown to include a reduction in precipitation for warm cloud systems when aerosols act only as CCN (Borys et al., 1998; Ferek et al., 2000; Kaufman and Nakajima, 1993; Rosenfeld, 2000; Heymsfield and McFarquhar, 2001). However, when aerosols are large enough to act as GCCN, the precipitation effects due to increased aerosol have been shown to reverse for warm 
clouds in polluted environments. For example, Feingold et al. (1999), Cheng et al. (2009), and Solomos et al. (2011) all found that when high concentrations of both $\mathrm{CCN}$ and GCCN were present, precipitation is increased. Once clouds reach temperatures that allow for ice processes to become important, the AIE becomes increasingly complex as more microphysical processes are involved, and the impacts of aerosols acting as IN need to be considered. Because it is difficult to quantify the AIE of mixed-phase cloud systems observationally (Rosenfeld and Feingold, 2003; Matsui et al., 2004; Berg et al., 2008), numerous modeling studies have been performed to enhance our understanding of such effects (Khain et al., 2005; van den Heever et al., 2006, 2011; van den Heever and Cotton, 2007; Lee et al., 2008; Storer et al., 2010; Solomos et al., 2011; Igel et al., 2012; Morrison, 2012; Storer and van den Heever, 2013). However, results from these studies have varied both in terms of convective invigoration and precipitation, which could be due to a number of factors (Morrison, 2012; Tao et al., 2012).

Despite the range in results that have been found for mixed-phase convective systems, a common factor amongst many of the modeling studies is that aerosols are typically represented as only one type of nucleating aerosol (Khain et al., 2005; van den Heever et al., 2011; Lee et al., 2008; Storer et al., 2010; Igel et al., 2012; Morrison, 2012; Storer and van den Heever, 2013). However, arguably the most abundant aerosol in our atmosphere, mineral dust (IPCC, 2001) has been found to act as CCN, GCCN, and IN (Twohy et al., 2009; DeMott et al., 2010), thereby potentially complicating the response. For example, van den Heever et al. (2006) and van den Heever and Cotton (2007) both found that, for continental deep convection, AIEs are highly variable and can change sign depending on the aerosol type involved.

While mineral dust is shown to have the highest concentrations close to its sources (desert regions; Tegen and Fung, 1994), it has been observed to traverse the globe over vast distances (e.g., the Saharan Air Layer (SAL)) thereby impacting a variety of convective systems (Prospero, 1996, 1999; Perry et al., 1997; Sassen et al., 2003; van den Heever et al., 2006; Carrio et al., 2007; Bangert et al., 2012). One such system, which has been found to be the leading heavyrain producer in the tropics and subtropics (Nesbitt et al., 2006), is the mesoscale convective system (MCS). While a number of studies have investigated AIEs on MCSs (Lynn et al., 2005a, b; Wang, 2005; Lee et al., 2008a, b, 2009; Li et al., 2009), little investigation regarding the specific impacts of mineral dust on MCSs has been performed. This is surprising considering the high frequency of MCS occurrence near the primary dust source regions of the world (Nesbitt et al., 2006).

The primary goal of this study is to assess the aerosol indirect effects of mineral dust on squall lines. As with previous studies of the microphysical impacts on squall lines (Morrison et al., 2009; Bryan and Morrison, 2012; Morrison et al., 2012; Seigel and van den Heever, 2013; van Weverberg et al., 2012), this will be achieved through idealized numerical modeling. In order to improve our understanding of the mineral dust AIE, recent model developments have been made to the microphysics and aerosol schemes in the model used in this study, the Regional Atmospheric Modeling System (RAMS). These now allow mineral dust particles to nucleate as both cloud drops and ice crystals (including immersion freezing), replenish upon evaporation and sublimation, be tracked throughout hydrometeor transition, and be scavenged by precipitation and dry sedimentation. This offers an excellent framework to explore in detail the microphysical and radiative processes responsible for the AIEs of a mixedphase cloud system, such as the squall line.

The role of radiation in squall line development and characteristics has been studied fairly extensively, the results of which indicate that radiation generally acts to strengthen squall lines due to increased instability from longwave cooling (Chen and Cotton, 1988; Dudhia, 1989; Tao et al., 1991, 1993; Chin, 1994; Dharssi et al., 1997). However, the role that radiation plays in squall lines due to changes in microphysical processes arising from the presence of aerosols is not well understood. Therefore, in order to isolate this role, as well as other mineral dust AIEs on squall lines, a suite of idealized cloud resolving model simulations is performed. The analysis of these simulations utilizes the technique of factor separation (Stein and Alpert, 1993; Alpert et al., 1995; Homar et al., 2003; van den Heever et al., 2006) to isolate the individual responses in the squall line that arise (1) from radiation, (2) from dust altering the microphysics, as well as (3) from the synergistic effects between (1) and (2). This study has deliberately removed the interaction between aerosols and radiation (the direct effect) due to the fact that we want to examine and isolate the more complex problem of aerosol indirect effects. The following section will describe in detail the new microphysical model developments for representing mineral dust, along with an introduction to factor separation and its use in this study. Section 3 will present the results of the simulations, and Sect. 4 will provide a discussion and summary of the work herein.

\section{Methods}

Four numerical simulations of an idealized squall line have been performed to assess the AIE of mineral dust. In order to obtain a realistic representation of mineral dust within the cloud-resolving model (CRM) used for this study, modifications have been made to its aerosol and microphysical schemes, the details of which are briefly described in this section following a short model description. Subsequently, the experimental design is presented. 


\subsection{Model description}

Given that the AIE stems from aerosols modulating microphysical processes within clouds, it is important to use a model that best simulates the microphysical processes observed in reality. This has been demonstrated to be most accurate when using bin-resolved microphysics (Khain et al., 2000; Morrison and Grabowski, 2007); however, the use of such schemes on scales that are required to simulate a three-dimensional squall line (i.e., $\sim 500 \mathrm{~km}$ ) is too computationally expensive with our current computing technology. As such, a model that is appropriate to simulate both the microphysics and the dynamics of a squall line is the non-hydrostatic Regional Atmospheric Modeling System (RAMS; Pielke et al., 1992; Cotton et al., 2003; Saleeby and Cotton, 2004). RAMS has a sophisticated bin-emulating, two-moment, bulk microphysical parameterization scheme that prognoses mass mixing ratio and number concentration for eight hydrometeor species (cloud droplets, drizzle, rain, pristine ice, snow, aggregates, graupel, and hail) (Walko et al., 1995; Meyers et al., 1997; Cotton et al., 2003; Saleeby and Cotton, 2004). The representation of numerous hydrometeor species with generalized gamma distributions helps to resemble the continuous spectrum of hydrometeors within the atmosphere (Flatau et al., 1989; Verlinde et al., 1990). For this study, a shape parameter $(v)$ value of two has been used for all species.

In order to gain bin representation of various processes while maintaining computational efficiency, RAMS utilizes look-up tables that have been previously generated offline. These include hydrometeor sedimentation (Feingold et al., 1998), liquid-to-liquid, liquid-to-ice, and ice-to-liquid collisions (Feingold et al., 1988), and cloud droplet nucleation from aerosol within a detailed bin-resolving parcel model (Feingold and Heymsfield, 1992; Saleeby and Cotton, 2004; Saleeby and van den Heever, 2013). Other schemes used in these simulations are radiative lateral boundary conditions (Klemp and Wilhelmson, 1978), a Rayleigh damping layer within the top six levels of the model domain with modifications by Lilly (1962) and Hill (1974), the Smagorinsky (1963) turbulence closure scheme, and Harrington (1997) two-stream radiation.

\subsection{Mineral dust scheme}

In RAMS, four aerosol species (ammonium sulfate, sodium chloride, mineral dust, and "regeneration") are represented. However, for simplicity sodium chloride is not used in this study. Mineral dust is unique in that the particles are predominantly insoluble and they often have large diameters, which assists their behavior as CCN, GCCN, and IN (Twohy et al., 2009; DeMott et al., 2010). As such, care has been taken in the representation of mineral dust within RAMS to ensure that it behaves similarly to what is seen in reality. As described in detail by Saleeby and van den Heever (2013), the mineral dust scheme includes parameterizations for surface dust emission from wind and saltation (not used in this study), dry deposition, and wet scavenging by precipitation and nucleation.

Mineral dust is represented as two separate distributions: one small and one large mode, the details of which are described in the next subsection. For nucleation scavenging, the number of nucleated aerosols is diagnosed using lookup tables that have been previously generated offline using a Lagrangian parcel bin model (Heymsfield and Sabin, 1989; Feingold and Heymsfield, 1992), and is based on the local vertical velocity, temperature, aerosol number concentration, aerosol median radius, and aerosol solubility fraction (Saleeby and Cotton, 2004; Saleeby and van den Heever, 2013). Table 1 describes the aerosol characteristics and microphysical parameters pertinent to this study.

If a dust particle acts as a $\mathrm{CCN}$ that is less than or equal to $1 \mu \mathrm{m}$ (radius), then a cloud droplet is formed that contains a dust particle. Similarly, if a dust particle is larger than $1 \mu \mathrm{m}$ (radius), the nucleated drop starts off as drizzle drop due to its large size; it also contains a dust particle. Since mineral dust is largely insoluble, the majority of the aerosol mass remains within the droplet in solid form. The dust mass is tracked through the various transitions between hydrometeor species. The insoluble mass within a drop is allowed to aid ice nucleation above the freezing level due to immersion freezing, which has shown to be an important ice nucleation mechanism (de Boer et al., 2010). Additionally, dry dust particles that have diameters greater than $0.5 \mu \mathrm{m}$ are allowed to serve as IN, so long as the limit of activated IN at the respective temperature has not been reached (DeMott et al., 2010). All heterogeneous nucleation of ice occurs following the parameterization of DeMott et al. (2010).

If a liquid drop or an ice crystal containing dust evaporates or sublimates, the dust mass is then added to the regenerated aerosol species. Due to the complicated nature of this aerosol regenerative process, assumptions have been made regarding the characteristics of these returned or regenerated aerosols, as multiple aerosol species could be present in any drop. Saleeby and van den Heever (2013) provides a thorough description of the microphysical and aerosol schemes.

\subsection{Experimental design}

In this study, four idealized simulations of a nocturnal squall line are performed to investigate its response to the addition of mineral dust and to the radiative feedback. All simulations are performed in three dimensions with a constant horizontal grid spacing of $500 \mathrm{~m}$ and stretched vertical grid spacing from $50 \mathrm{~m}$ to $500 \mathrm{~m}$. The model domain covers a volume of $500 \times 150 \times 26 \mathrm{~km}$ in the zonal, meridional, and vertical directions, respectively. The time step used is $3 \mathrm{~s}$, and time integration is performed for $7 \mathrm{~h}$ nocturnally, as this is the peak occurrence time of MCSs (Laing and Fritsch, 1997; Anderson and Arritt, 1998; Jirak et al., 2003). 
Table 1. Overview of microphysical parameterizations and parameters used in all simulations.

\begin{tabular}{ll}
\hline Attribute & Value \\
\hline Prognosed hydrometeor species & $\begin{array}{l}\text { Cloud droplets, drizzle drops, } \\
\text { rain drops, pristine ice crystals, } \\
\text { snow, aggregates, graupel, and } \\
\text { hail }\end{array}$ \\
\hline $\begin{array}{l}\text { Shape parameter, } v \text {, for gamma functions of all hydrometeor } \\
\text { species }\end{array}$ & 2 \\
\hline Assumed dust solubility & $5 \%$ \\
\hline Log-normal dust mode 1 median diameter & $0.1 \mu \mathrm{m}$ \\
\hline Log-normal dust mode 2 median diameter & $0.95 \mu \mathrm{m}$ \\
\hline Heterogeneous ice nucleation parameterization & DeMott et al. (2010) \\
\hline
\end{tabular}

Squall line initiation is performed using a framework similar to other previous idealized studies (Trier et al., 1997; Fierro et al., 2008; Morrison et al., 2009; Seigel and van den Heever, 2013). The model domain is initialized with horizontally homogenous temperature and moisture profiles following Weisman and Klemp (1982), but with a boundary layer temperature profile that has been adjusted to mimic a well-mixed boundary layer, which better represents the real environment that such systems form in (Fig. 1). The shear profile used for initialization has a linear increase from 0 to $12.5 \mathrm{~m} \mathrm{~s}^{-1}$ in the lower $2.5 \mathrm{~km}$ (Fig. 1) and is within the range used by previous studies (Weisman, 1992, 1993; Weisman and Rotunno, 2004; Frame and Markowski, 2006; Bryan et al., 2007). The squall lines are initiated using a $4 \mathrm{~km}$ deep, $-6 \mathrm{~K}$ line thermal resting on the surface, representing a cold pool, and containing random embedded $-0.1 \leq \theta \leq$ 0.1 potential temperature $(\theta)$ perturbations to initiate threedimensional motions.

Aerosol data measured near one of the largest dust source regions in the world, the Sahara, are used to represent the nucleating species of sulfates and mineral dust within RAMS. These data were collected from the NASA African Monsoon Multidisciplinary Analyses (NAMMA; Zipser et al., 2009) experiment in 2006 (C, Twohy, personal communication, 2012), and are a good sampling of the SAL (Ismail et al., 2010). Figure 2 shows the vertical profiles and distributions (number and mass) of the aerosol concentrations for sulfate, small dust, and large dust particles. The treatment of dust for each simulation is described later in this subsection.

In order to more fully understand how mineral dust impacts the simulated squall line, factor separation (Stein and Alpert, 1993) is used to isolate the contributions from the following: (1) the inclusion of radiative transfer, while excluding mineral dust (herein referred to as RADIATION), (2) dust altering microphysical processes but not the subsequent radiative responses (herein referred to as DUST MICRO), and (3) the nonlinear interactions between dust altering micro-

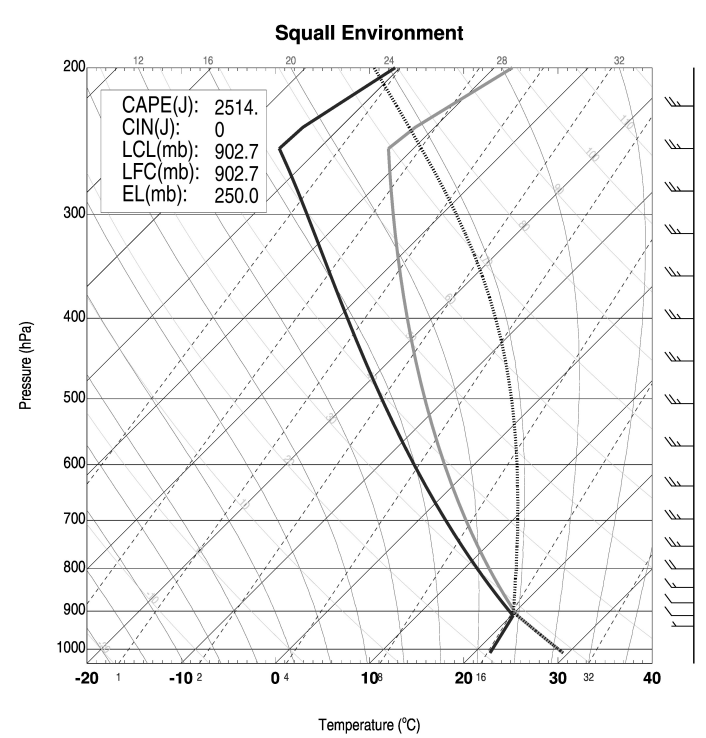

Fig. 1. Horizontally homogeneous environmental conditions initialized for the squall line. The thick gray line is the temperature profile and the thick black is the moisture profile. The thick dashed line is the adiabatic parcel curve (following Weismann and Klemp, 1982).

physical processes and radiative transfer (herein referred to as SYNERGY). This has been shown to be an effective technique in other previous studies of deep convection (Romero et al., 1998; Homar et al., 2003; van den Heever et al., 2006). It is important to stress that SYNERGY is not merely the sum of RADIATION and DUST MICRO, but rather it is an additional contribution that is purely due to the nonlinear interactions between the two forcing mechanisms.

Let us consider a simple, hypothetical example that demonstrates a single synergistic contribution from a framework similar to the research herein. It is well known that dust acts as IN and that anvil clouds radiatively cool near cloud top due to longwave emission by condensate, mainly in the 

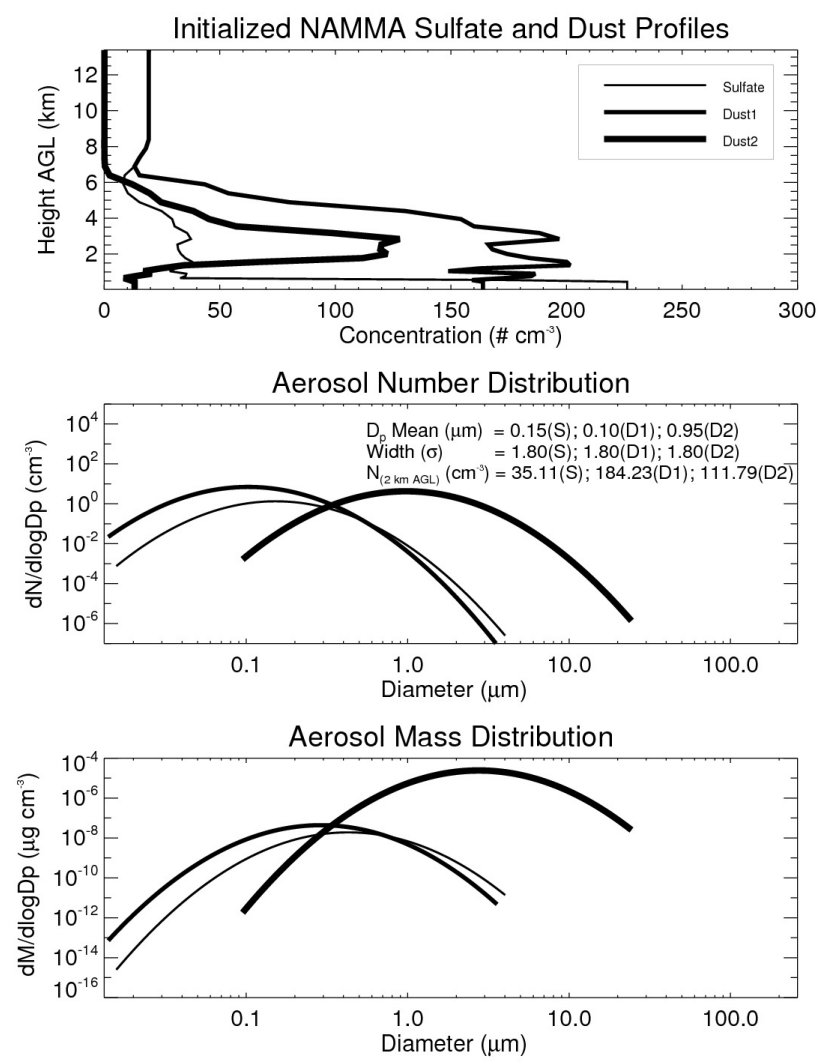

Fig. 2. Aerosol data from NASA African Monsoon Multidisciplinary Analyses (NAMMA) in 2006. The three aerosol species represented in the study are sulfate (thin), small dust (medium thickness), and large dust (thick). Top: the initialized horizontally homogeneous profiles $\left(\mathrm{cm}^{-3}\right)$; middle: aerosol number distribution at $2 \mathrm{~km}$ a.g.l.; and bottom: aerosol mass distribution at $2 \mathrm{~km}$ a.g.l. Also shown in (middle) are the geometric mean particle diameter, distribution width parameter, and the total number concentration for sulfate (S), Dust1 (D1), and Dust2 (D2).

form of ice. From this, it could be expected that the sole inclusion of radiative transfer in a nocturnal squall line simulation (i.e., RADIATION) would act to cool the anvil, thereby increasing supersaturation and facilitating ice crystal growth. Similarly, it could be expected that the impacts of the sole inclusion of dust (i.e., DUST MICRO) on the anvil would act to increase ice crystal number concentrations and subsequently alter the ice crystal size distributions and microphysical processes within the anvil. Now, the synergistic contribution from radiative transfer and dust (i.e., SYNERGY) within the anvil is more complex, as nonlinear interactions often occur. For example, because radiative cooling enhances supersaturation in the anvil, the additional cooling may help to nucleate more dust particles relative to the situation in which only the inclusion of dust is considered. The additional ice crystals produced through this synergistic response may then act to further enhance cloud top cooling over and above that produced in RADIATION due to increases in ice crystal sur- face area and number concentration. This hypothetical example represents one possible nonlinear interaction represented by the synergy term that may result from the sensitivity experiments herein.

In order to fully quantify the three previously discussed contributions to the squall line (RADIATION, DUST MICRO, and SYNERGY), four sensitivity experiments are conducted in which the inclusion of radiation and microphysically active dust is systematically toggled. The description and name of each simulation is shown in Table 2, where the following information further describes the experiments:

- when dust is microphysically active, the full dust scheme is used and includes dust nucleating as liquid drops and ice crystals, dry deposition, and precipitation scavenging;

- when dust is not microphysically active, then dry deposition and precipitation scavenging are the only dust removal mechanisms;

- when radiation is turned off, the tendencies to the temperature field from radiative processes are not included; furthermore, radiation is not allowed to interact with the microphysics.

In order to most effectively isolate the AIE using factor separation on the four simulations, dynamic land surface interaction is excluded for all simulations and is replaced by fixed values of surface temperature $(300 \mathrm{~K})$ and soil moisture (35\% volumetric content). A constant roughness length of 0.05 is used to simulate the effects of surface friction over grass and brush, which is a common land surface for MCSs in semi-arid regions (Masson et al., 2003). Coriolis forcing is also excluded for all experiments to keep the squall line flow predominantly perpendicular to the meridionally oriented cold pool for more straightforward analysis. Additionally, as the focus of the study is solely on aerosol indirect effects and not aerosol direct effects, dust and sulfates are not radiatively active for all simulations.

The calculations used to isolate the factors described above are shown in Table 3, along with the naming convention that is used throughout the remaining sections. The term "the factor(s)" refers to the contributions to the squall line from the calculations of RADIATION, DUST MICRO, and SYNERGY (Table 3), and not the simulations of dOffrOff, dOnrOff, dOffrOn, and dOnrOn (Table 2). The phrase "part of the predicted field" in Table 3 is intended to indicate that this is part of the full field (e.g., precipitation, total condensate mixing ratio, etc.) due to the factor. These calculations are applied to the group of simulations in a variety of ways (e.g., domain-averaged fields, cloudy region averages, etc.) and will be described with respect to each analysis type. 


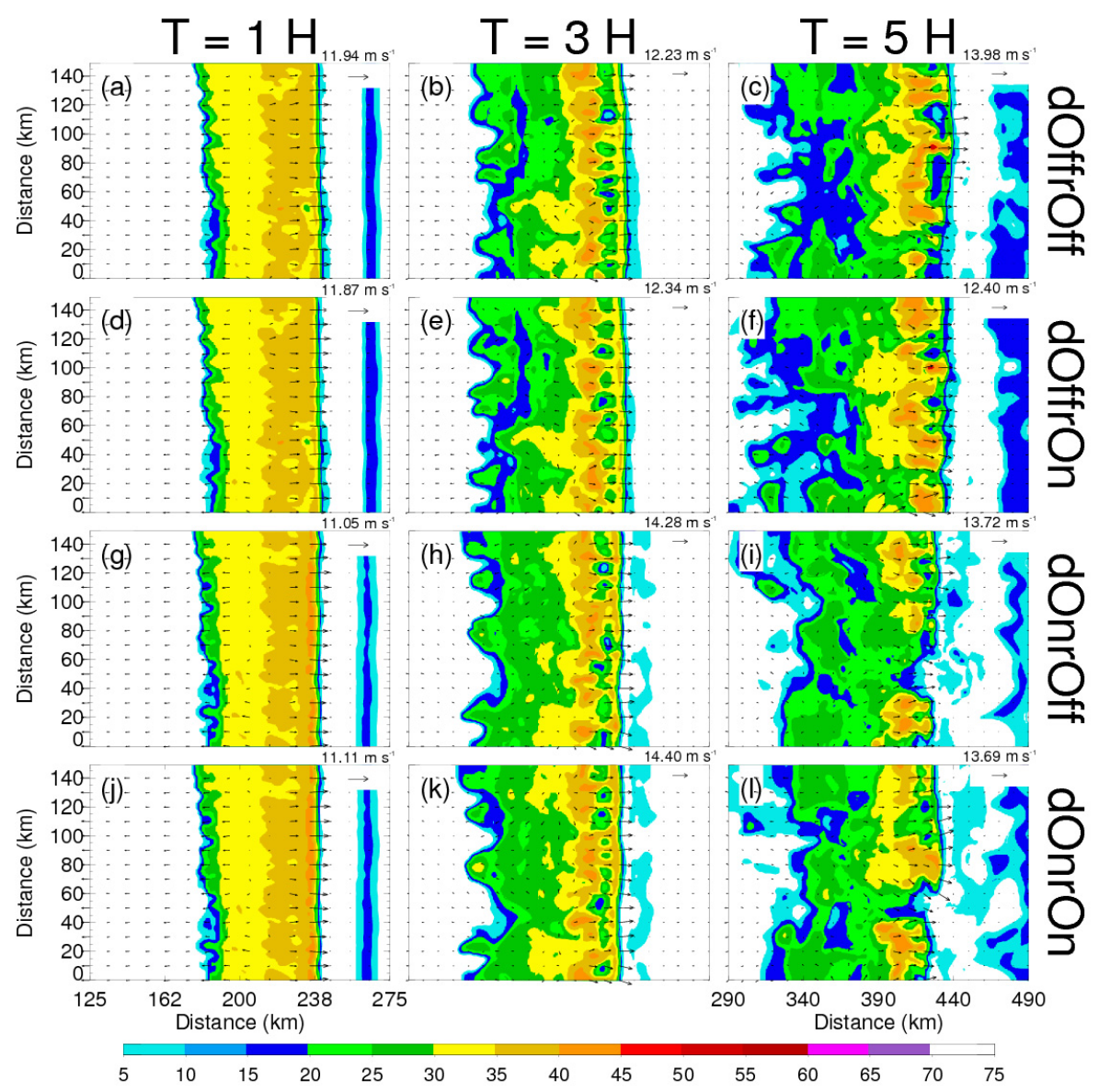

Fig. 3. Simulated base radar reflectivity (dBZ; Matrosov, 1999) of dOffrOff (a-c), dOffrOn (d-f), dOnrOff (g-i), and dOnrOn (j-l) at

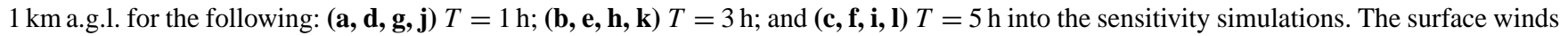
are shown (vectors) along with the maximum surface wind reference vector in the upper-right corner for each image.

Table 2. Description and naming convention of the four experiments.

\begin{tabular}{ll}
\hline Name & Description \\
\hline dOffrOff & - Dust acting as CCN and IN is OFF \\
& - Radiation is OFF \\
\hline dOffrOn & - Dust acting as CCN and IN is OFF \\
& - Radiation is ON \\
\hline dOnrOff & - Dust acting as CCN and IN is ON \\
& - Radiation is OFF \\
\hline dOnrOn & - Dust acting as CCN and IN is ON \\
& - Radiation is ON \\
\hline
\end{tabular}

\section{Results}

This section presents results from a factor separation analysis of four simulations of an idealized nocturnal squall line. In order to provide a controlled setup of the experiment, a single squall line simulation was used as the benchmark squall line for the sensitivity experiments. This benchmark simulation is run for $2 \mathrm{~h}$ and includes the full dust scheme and the effects of radiation. After $2 \mathrm{~h}$, the squall line has matured and the model is restarted using those data as the initial conditions for each of the four sensitivity experiments: dOffrOff, dOnrOff, dOffrOn, and dOnrOn (Table 2). For those analyses in this section that utilize time averaging, the first hour of each sensitivity experiment has been excluded in order to provide sufficient time for the squall line physics to evolve from the benchmark simulation. Furthermore, some of the analyses provided in this section are susceptible to local shifts of microphysical processes. Because of these shifts, zonally averaged values are also provided and discussed in order to obtain bulk assessments of the presented analyses. The results in this section are compartmentalized into two subsections that first describe the changes in the general characteristics and dynamics of the squall line due to the factors, and then describe the microphysics and thermodynamics responsible for those changes. 
Table 3. The components and naming convection of the factor separation analysis.

\begin{tabular}{llll}
\hline Factor & Name & Description & Calculation \\
\hline$f_{0}$ & CONTROL & $\begin{array}{l}\text { Part of the predicted field independent } \\
\text { from dust altering the microphysics and } \\
\text { radiation }\end{array}$ & $f_{0}=$ dOffrOff \\
\hline$f_{1}$ & RADIATION & $\begin{array}{l}\text { Part of the predicted field from the sole } \\
\text { contribution of radiation }\end{array}$ & $f_{1}=$ dOffrOn - dOffrOff \\
\hline$f_{2}$ & DUST MICRO & $\begin{array}{l}\text { Part of the predicted field from the sole } \\
\text { contribution of dust altering the micro- } \\
\text { physics }\end{array}$ & $f_{2}=$ dOnrOff - dOffrOff \\
\hline$f_{12}$ & SYNERGY & $\begin{array}{l}\text { Part of the predicted field from the syn- } \\
\text { ergistic effects of dust altering the mi- } \\
\text { crophysics and radiation }\end{array}$ & $\begin{array}{l}f_{12}=\text { dOnrOn } \\
-(\text { dOnrOff }+ \text { dOffrOn }) \\
+ \text { dOffrOff }\end{array}$ \\
\hline
\end{tabular}

\subsection{General characteristics and dynamics}

The four squall line evolutions are consistent and characterized as a classic trailing stratiform squall line (Parker and Johnson, 2000). Figure 3 shows $1 \mathrm{~km}$ a.g.l. simulated radar reflectivity (Matrosov, 1999) and surface winds for the squall lines after 1,3 , and $5 \mathrm{~h}$ into each simulation. It can be seen that all four squall lines have a leading line of high reflectivity that is trailed by a $\sim 100 \mathrm{~km}$ wide region of lower reflectivity, consistent with the categorization of MCSs (Houze, 1993; Parker and Johnson, 2000). It can also be seen that the squall lines that include microphysically active dust (dOnrOff and dOnrOn) begin with stronger reflectivity values leading the convective line, but at the end of the time integration, the two squall lines appear to be breaking up and weakening (compare Fig. $3 \mathrm{c}$ and $\mathrm{f}$ with Fig. $3 \mathrm{i}$ and $\mathrm{l}$ ).

To begin the assessment of squall line intensity, Fig. 4 shows the contributions to precipitation from the factors as meridionally averaged Hovmöller diagrams, along with the full precipitation field of the CONTROL simulation (dOffrOff). The CONTROL simulation exhibits the classic characteristics of accumulated precipitation for a trailing stratiform squall line, where (1) a narrow region of enhanced precipitation occurs at the leading edge due to warm-rain formation, and (2) a precipitation minimum occurs behind the convective line (often referred to as the transition zone) that is followed by another local maximum in precipitation from ice processes (Fig. 4a). Including the effects of radiation (RADIATION; Fig. 4b) acts to increase precipitation for the entire squall line on average by up to $25 \%$, which is consistent with other studies (Tao et al., 1991, 1993; Dharssi et al., 1997). The inclusion of microphysically active dust (DUST MICRO) contributes to the precipitation field in three ways (Fig. 4c): (1) it initially enhances convective precipitation (up through the first $2.5 \mathrm{~h}$ ); (2) it systematically decreases the stratiform precipitation; and (3) it reduces the domain mean precipitation during the second half of the experiment by up
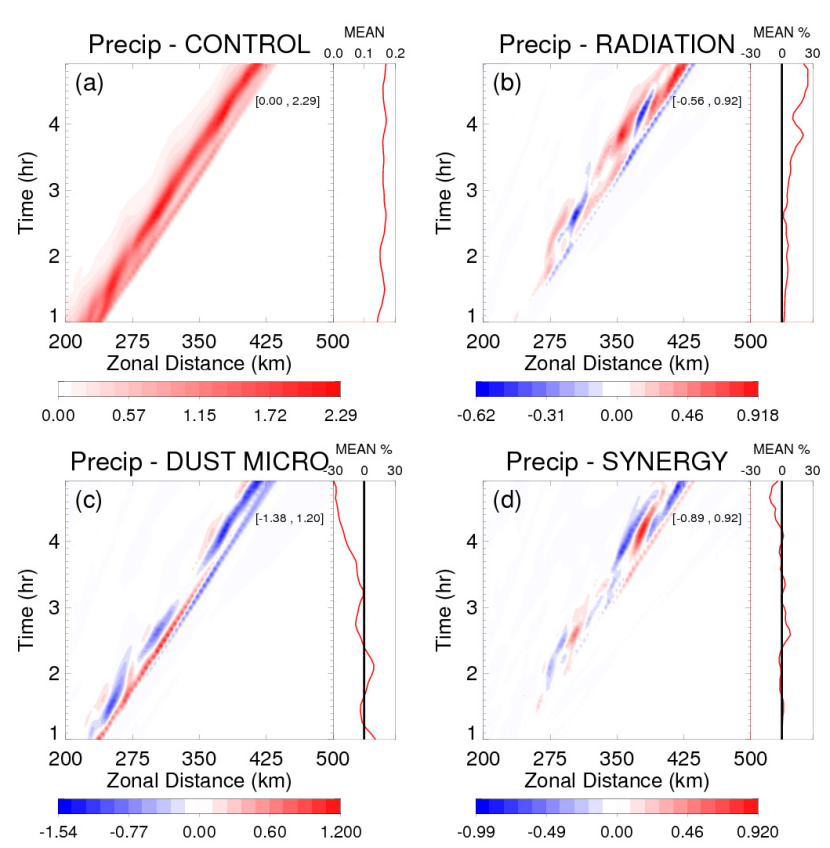

Fig. 4. Meridionally averaged accumulated precipitation (mm $5 \mathrm{~min}^{-1}$ ) for the four factors of (a) CONTROL, (b) RADIATION, (c) DUST MICRO, and (d) SYNERGY. See Tables 1 and 2 for factor descriptions. The accumulated precipitation is expressed both as a Hovmöller diagram (shading) and a zonally averaged time series that is expressed as a percent contribution relative to CONTROL (line plot).

to $30 \%$. Furthermore, the synergistic contribution to precipitation from microphysically active dust and radiation (SYNERGY; Fig. 4d) is not overall very large, and is characterized by a brief increase in precipitation between hours two and three followed by a decrease towards the end of time integration by up to $15 \%$.

The cold pool has been shown to play an integral role in the organization and structure of squall lines (Thorpe et al., 1982; 

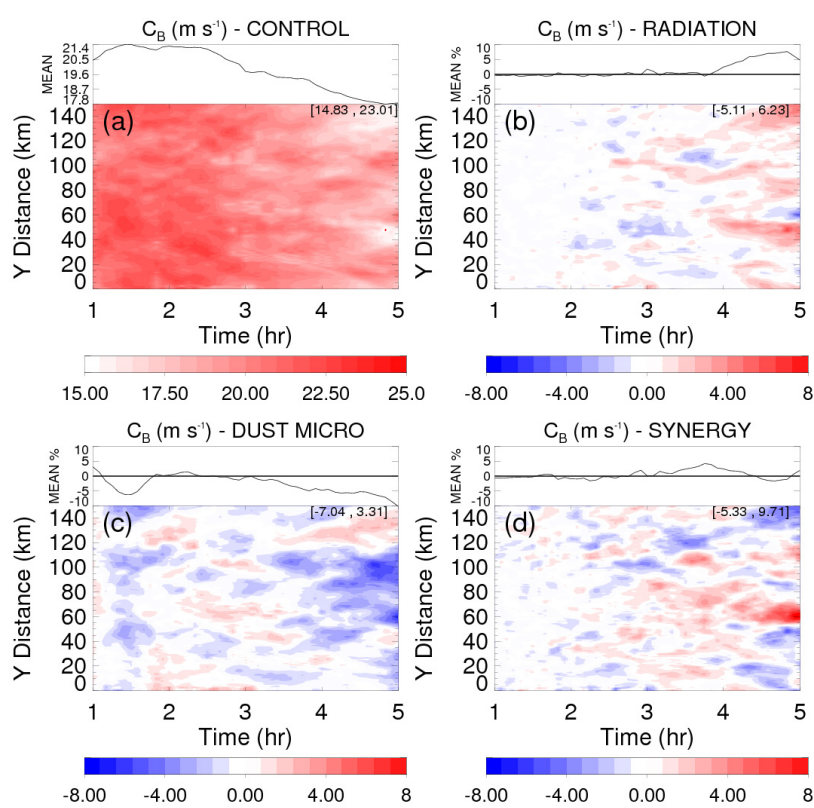

Fig. 5. Theoretical cold pool speed, which is defined in Eq. (1), shown for the four factors of (a) CONTROL, (b) RADIATION, (c) DUST MICRO, and (d) SYNERGY. The cold pool speed is expressed as both a rotated Hovmöller diagram (shading) and a meridionally averaged time series that is expressed as a percent contribution relative to CONTROL (line plot).

Rotunno et al., 1988, 1990; Weisman et al., 1988; Weisman, 1992, 1993; Weisman and Rotunno, 2004, 2005; Bryan et al., 2006). To assess each factor's contribution to the cold pool speed of the squall line, a traditional measure of cold pool speed is used (e.g., Rotunno et al., 1988; Weisman and Rotunno, 2004; Bryan et al. 2006) that is based on density current theory and is given by (Benjamin, 1968)

$C_{\mathrm{B}}^{2}=2 \int_{0}^{H}(-B) \mathrm{d} z$,

where $C_{\mathrm{B}}$ represents the cold pool propagation speed, $H$ represents the depth of the cold pool, and $B$ represents buoyancy, which is calculated following Tompkins (2001). The cold pool boundary is defined by the $-0.05 \mathrm{~m}^{2} \mathrm{~s}^{-2}$ buoyancy surface. The speed of the cold pool of CONTROL (Fig. 5a) ranges from $\sim 15-23 \mathrm{~m} \mathrm{~s}^{-1}$, and agrees well with other studies using the same thermodynamic profile as used here (e.g., Weisman and Rotunno, 2004; Bryan et al., 2006).

The factor separation analysis for cold pool speed shows a trend similar to that for precipitation for the contributions of RADIATION, DUST MICRO and SYNERGY (Fig. 5). On average, RADIATION generally does not contribute to a substantial change in cold pool speed until the final hour of the experiment, whereby an increase of up to $8 \%$ occurs (Fig. 5b). DUST MICRO acts to initially increase the cold
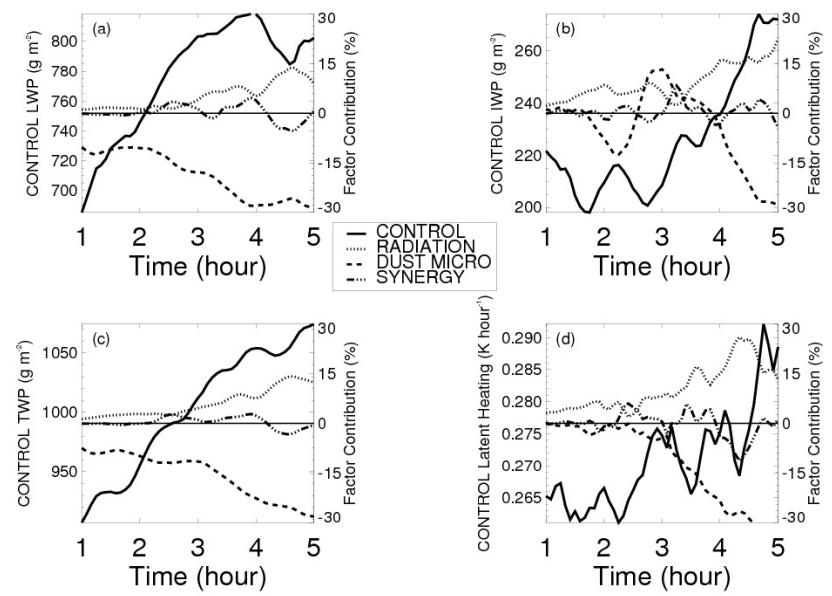

Fig. 6. Domain-averaged time series of (a) liquid water path $\left(\mathrm{g} \mathrm{m}^{2}\right)$, (b) ice water path $\left(\mathrm{g} \mathrm{m}^{2}\right)$, (c) total water path $\left(\mathrm{g} \mathrm{m}^{2}\right)$, and (d) troposphere depth normalized, vertically integrated latent heating rate $\left(\mathrm{K} \mathrm{h}^{-1}\right)$. The solid lines correspond to CONTROL with the full field values on the left axes. The dotted (RADIATION), dashed (DUST MICRO), and dot-dashed (SYNERGY) lines correspond to the factors and are expressed as a percent contribution to CONTROL shown on the right axes.

pool speed for the first hour; and is then followed by a decrease in cold pool speed throughout the remainder of time integration (Fig. 5c). SYNERGY's contribution to cold pool speed is not large and contains a maximum change in $C_{\mathrm{B}}$ of $\sim 5 \%$ (Fig. 5d). This small change in cold pool speed is largely due to the small changes in condensate due to SYNERGY, which will be discussed in greater detail in the next subsection.

It has been shown that cold pool intensity and precipitation of squall lines are both dependent on various microphysical processes (Morrison et al., 2009; Bryan and Morrison, 2012; Morrison et al., 2012; Adams-Selin et al., 2013a, b; van Weverberg et al., 2012). As such, in order to obtain a bulk perspective of the microphysics governing the squall line, Fig. 6 shows factor separation analyses of domain-averaged condensate paths and latent heating. The contributions to liquid water path (LWP) show consistent trends in time relative to CONTROL, whereby RADIATION increases LWP by up to $13 \%$, DUST MICRO removes up to $\sim 28 \%$ of LWP, and SYNERGY has an oscillatory and overall neutral contribution to LWP. With respect to ice processes, RADIATION shows a systematic increase in ice water path (IWP) in time; at the end of experiment, RADIATION contributes up to a $22 \%$ increase in IWP. An increase in squall line ice due to the inclusion of longwave radiation has also been seen by Tao et al. (1991, 1993), and will be further investigated later in this section. Both DUST MICRO and SYNERGY show a largely oscillatory response in contribution to IWP, except during the last hour where DUST MICRO dramatically reduces the IWP of the squall line, which is primarily due to 
the demise of the dOnrOff squall line from the significant weakening of the surface cold pool (Fig. 3i). The total water path (TWP) contributions from the factors indicate that RADIATION increases TWP (up to $14 \%$ ), DUST MICRO reduces TWP (up to $28 \%$ ), and SYNERGY again has an oscillatory contribution with small changes in time.

The changes in TWP will contribute to differences in latent heating (LH) that can alter the dynamics and intensity of the squall line. As such, a troposphere depth-normalized, vertically integrated LH rate is shown in Fig. 6d to gain a bulk perspective of LH. Similar to TWP, RADIATION invigorates the squall line latent heating and contributes to an enhancement of up to $26 \%$. DUST MICRO has a neutral contribution to latent heating through the first $2.5 \mathrm{~h}$, as opposed to an expected negative contribution based on the decrease in TWP during this time. This discrepancy is explained by DUST MICRO's contribution to precipitation, where an enhancement in the convective precipitation during the first $2.5 \mathrm{~h}$ effectively removed the water from the squall line that already contributed to the total latent heat release. The SYNERGY contributions to latent heating are relatively insignificant and have an oscillatory nature.

To better understand how the factors are contributing to the structure and organization of the squall line, Fig. 7 shows vertical profiles of various temporal and domain-averaged fields from cloud base $(\sim 1 \mathrm{~km}$ a.g.l.) up to just below the tropopause $(\sim 10 \mathrm{~km}$ a.g.l.), which are expressed as percent contributions to the squall line. The zonal wind field $(U$; Fig. 7a) of CONTROL has the classic structure of a wellorganized squall line that is contributing to convective momentum transport (CMT; Lane and Moncrieff, 2010). This can be seen by a local maximum in $U \sim 3 \mathrm{~km}$ a.g.l. due to the rear-to-front flow of the rear inflow jet (RIJ), and a local minimum in $U$ within the anvil region $\sim 7 \mathrm{~km}$ a.g.l. due to the front-to-rear (FTR) flow of the squall line within the updraft. As such, a positive contribution to the RIJ or a negative contribution to the FTR flow enhances the mesoscale organization of the squall line. From Fig. 7a, it can be seen that RADIATION most positively contributes to the CMT of the squall line, which is consistent with other previous studies (Chen and Cotton, 1988; Dudhia, 1989; Chin, 1994; Dharssi et al., 1997). DUST MICRO significantly weakens the kinematic organizational structure of the squall line, which corroborates the demise of the dOnrOff squall line due to a weaker cold pool. While SYNERGY has thus far indicated no significant contribution to the squall line, it has a slightly positive contribution to the CMT of the squall line.

The mean vertical velocity ( $W$; Fig. $7 \mathrm{~b}$ ) of CONTROL is positive everywhere and peaks in the middle troposphere. The contribution to $W$ by RADIATION is generally positive throughout the depth of the troposphere, except near the top of the anvil where longwave cooling produces sinking motion. DUST MICRO negatively contributes to $W$ up through $5 \mathrm{~km}$ a.g.l., but positively contributes to $W$ within the $5-9 \mathrm{~km}$ a.g.l. layer, indicating that ice processes may be play-
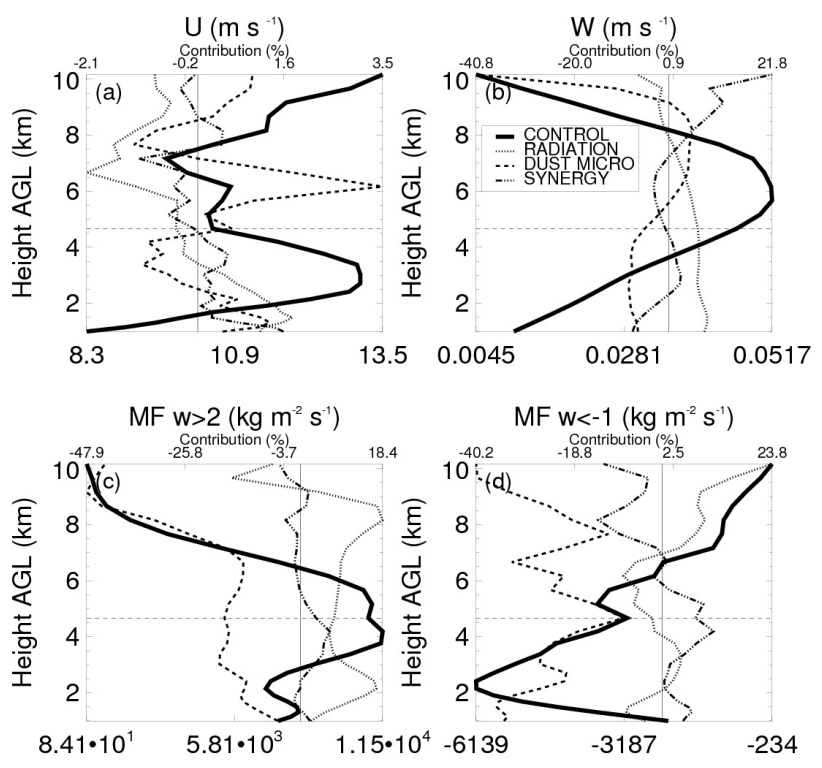

Fig. 7. Domain-averaged vertical profiles of (a) zonal wind $\left(\mathrm{m} \mathrm{s}^{-1}\right)$, (b) vertical velocity $\left(\mathrm{m} \mathrm{s}^{-1}\right)$, (c) total convective mass flux sampled where $W>2 \mathrm{~m} \mathrm{~s}^{-1}\left(\mathrm{~kg} \mathrm{~m}^{-2} \mathrm{~s}^{-1}\right)$, and (d) total downdraft mass flux sampled where $W<-1 \mathrm{~m} \mathrm{~s}^{-1}\left(\mathrm{~kg} \mathrm{~m}^{-2} \mathrm{~s}^{-1}\right)$. The solid lines correspond to CONTROL with the full field values on the bottom axes. The dotted (RADIATION), dashed (DUST MICRO), and dot-dashed (SYNERGY) lines correspond to the factors and are expressed as a percent contribution to CONTROL on the top axes.

ing a large role. SYNERGY slightly increases the low-level $W \sim 3 \mathrm{~km}$ a.g.l. and slightly decreases $W$ around $6 \mathrm{~km}$ a.g.l., which may highlight a change to convective organization of the squall line.

By sampling the squall line for grid cells that have strong updrafts and strong downdrafts, a more in-depth assessment of squall line invigoration and convective organization can be made. Figure 7c shows the profile of total mass flux (MF), sampled where updrafts are greater than $2 \mathrm{~m} \mathrm{~s}^{-1}$ (i.e., convective mass flux, CMF). It is evident that RADIATION acts to enhance the CMF by up to $18 \%$. DUST MICRO decreases the CMF substantially throughout the troposphere, while SYNERGY generally has a neutral contribution to CMF except near the freezing level where it increases CMF by up to $8 \%$ at $\sim 4 \mathrm{~km}$ a.g.l. Conversely, by sampling the squall line where vertical velocity is less than $-1 \mathrm{~m} \mathrm{~s}^{-1}$, Fig. $7 \mathrm{~d}$ shows the mean downdraft mass flux (DMF) profile that helps to both transport momentum towards the surface from aloft and enhance the cold pool (Smull and Houze, 1987; Weisman, 1992). Where the CONTROL mesoscale downdraft is maximized (2-4 km a.g.1.), RADIATION positively contributes to DMF, DUST MICRO negatively contributes to DMF by up to $30 \%$, and SYNERGY positively contributes to DMF. The contributions by the factors to both CMF and DMF match well with the contributions by the factors to the zonal wind, further confirming that DUST MICRO reduces CMT while 
SYNERGY enhances CMT. The reasons for these contributions are due to changes in microphysical processes and will be discussed in the next subsection.

From this subsection, the two factors involved with the mineral dust AIE on a nocturnal squall line, DUST MICRO and SYNERGY, act to weaken and slightly strengthen the squall line, respectively. Because the contributions due to SYNERGY are relatively small, the combined contributions of DUST MICRO and SYNERGY (i.e., the aerosol indirect effects) lead to an overall weakening of the squall line in the presence of mineral dust. Conversely, the contribution of RADIATION is shown to invigorate the simulated squall line and matches well with past studies. The following subsection will explain in detail the microphysical processes responsible for the behavior of the factors (RADIATION, DUST MICRO, and SYNERGY) just discussed.

\subsection{Microphysical response}

Before analyzing the microphysical processes responsible for the behaviors of each factor just described, it is necessary to illustrate and describe how mineral dust is processed microphysically within the squall line. Figure 8 shows a meridionally and temporally averaged view of the dOnrOn squall line experiment. The microphysical processing of mineral dust acting as CCN and GCCN by the squall line begins by nucleating cloud and drizzle drops in the inflow region of the squall line (Fig. 8a). The dust within cloud and drizzle (Fig. 8b) can then be tracked through the warm rain process as collision-coalescence generates raindrops (Fig. 8c). This collision-coalescence process ultimately removes much of the dust through precipitation and may help to explain why DUST MICRO weakens the squall line due to a loss of potential IN. However, some dust does remain within cloud, drizzle, and rain that can be followed to hail through riming processes near the freezing level within the updraft (Fig. 8d; Seigel and van den Heever, 2013).

A second pathway of dust processing by the squall line occurs when dust acts as IN, and first occurs as pristine ice crystals nucleate near cloud top (Fig. 8e). Through vapor deposition, pristine ice grows into snowflake-size crystals (Fig. 8f). As the snow containing dust sedimentates lower and resides longer in the anvil, ice crystal aggregation occurs because of increased probability of collection (Fig. 8g). The larger aggregates are transported rearward, while sedimentating towards the freezing level where increased riming by supercooled droplets can occur. This changes the dust-laden aggregates into graupel particles containing dust once sufficient riming has occurred (Fig. 8h). In the wake of the squall line surrounding the freezing level, a portion of the ice particles, snow, aggregates, graupel, and hail can sublimate, thereby releasing the dust particles back into the atmosphere as regenerated aerosol (Fig. 8i).

It is worth mentioning that the dust concentrations within the hydrometeor species are significantly different when dust is not microphysically active, as in dOffrOn and dOffrOff. When dust is not allowed to nucleate as CCN, GCCN, or IN, the only wet mechanism by which dust is removed is through collisions either within the cloud or by the precipitation shaft. This removal efficiency is small in comparison to that from nucleation. When dust is allowed to nucleate, as in dOnrOn and dOnrOff, nearly all of the dust within the squall line is removed by the updraft. This is because the updraft of the squall line is so strong ( $\sim 30 \mathrm{~m} \mathrm{~s}^{-1}$ at times). Large supersaturations are generated and all dust particles are nucleated into cloud or drizzle drops. Therefore, the wet deposition rates differ by orders of magnitude between [dOnrOn, dOnrOff] and [dOffrOn, dOffrOff].

A factor separation analysis has been performed on each hydrometeor species' domain-averaged path (i.e., a densityweighted, vertically integrated mass) in order to gain insight into the microphysical processes responsible for the changes in dynamics discussed in the previous subsection. The contributions to each hydrometeor's mass by the factors are expressed as a percent change relative to CONTROL (Fig. 9). RADIATION increases the mass of all the hydrometeor types and adds $6 \%$ to the total condensate of the squall line. DUST MICRO negatively contributes to each hydrometeor species' mass with a total condensate contribution of $-16 \%$, which is predominantly due to the liquid species. SYNERGY's contribution is predominantly positive; however, the total condensate contribution is small (less than $1 \%$ ).

As a first step to understanding why these changes in condensate are occurring due to radiative and microphysical impacts by the factors, Fig. 10 shows a temporally and meridionally (following the gust front) averaged vertical cross section of the total condensate mixing ratio (henceforth referred to as only total condensate) distribution within the squall line. Relative to CONTROL (Fig. 10a), it can be seen that the factors alter the total condensate distribution of the squall line in multiple ways. RADIATION increases total condensate throughout the depth of the troposphere (Fig. 10b). This is maximized near cloud top (30\% increase) due to cloud top radiational cooling (Fig. 11) that acts to destabilize the anvil region (Churchill and Houze, 1991), thereby promoting increased ice supersaturation that helps to grow condensate by vapor deposition. Additionally, a local maximum in total condensate enhancement occurs $\sim 3 \mathrm{~km}$ a.g.l. that appears to lead to a heavier precipitation shaft. This matches well with the overall increase in precipitation (Fig. 4b) and cold pool intensity (Fig. 5b), indicating that enhanced precipitation production leads to increased evaporational cooling that drives a stronger cold pool and squall line.

Consistent with the individual contributions to hydrometeor mass, DUST MICRO decreases the zonally averaged total condensate throughout the depth of the troposphere. Locally, DUST MICRO increases total condensate near the gust front, decreases the trailing stratiform precipitation, and greatly reduces total condensate just below the freezing level in the wake of the cold pool-forced updraft (Fig. 10c). It is 

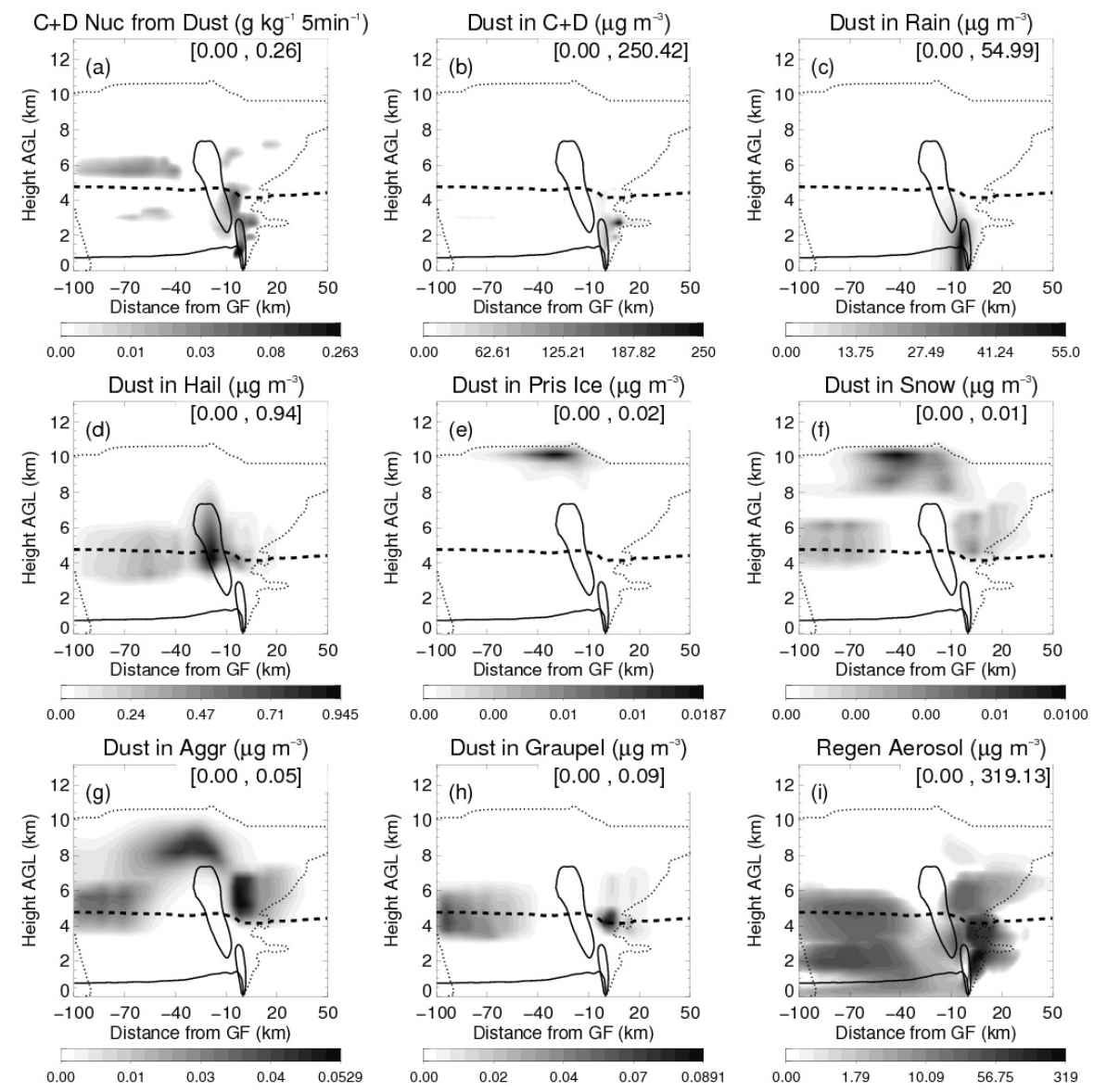

Fig. 8. The dOnrOn squall line, which has been averaged both meridionally along the gust front (GF) and temporally from sensitivity simulation hours 1-5. Each vertical cross section is expressed as a horizontal distance from the gust front (x-axis) and a vertical distance a.g.l. (y-axis). Shown on each cross section is the squall line cloud boundary (dotted line; $0.05 \mathrm{~g} \mathrm{~kg}^{-1}$ total condensate), the freezing line (dashed black line), the cold pool boundary (thin black line below $2 \mathrm{~km} \mathrm{a.g.1.;}-0.05 \mathrm{~m}^{2} \mathrm{~s}^{-2}$ following Tompkins (2001)), the $1 \mathrm{~m} \mathrm{~s}{ }^{-1}$ updraft region (thick black lines stemming from the gust front), and (min, max) values for the shaded quantities of the following: (a) cloud and drizzle $(\mathrm{C}+\mathrm{D})$ nucleation rate by dust; (b) dust within $\mathrm{C}+\mathrm{D}$; (c) dust within rain; (d) dust within hail; (e) dust within pristine ice; (f) dust within snow; (g) dust within aggregates; (h) dust within graupel; and (i) concentration of regeneration aerosol. The units are shown in the figure for each quantity.

interesting that while an increase in condensate occurs near the gust front, the cold pool intensity weakens due to DUST MICRO. This further highlights the importance of the ice phase in maintaining cold pool intensity through melting and sub-cloud evaporation, as the precipitation originating from ice processes is reduced in this simulation $(\sim-20-30 \mathrm{~km}$ from GF in Fig. 10c). The physics governing these responses in the squall line total condensate will be discussed in more detail later in this section.

For SYNERGY, while large positive and negative contributions occur locally, its average contribution to total condensate is relatively minor (Fig. 10d). However, there is a general increase in total condensate (1) just above the freezing level, which is due to an increase in hail mass (Fig. 9), and (2) near cloud top, which is due to an increase in mass of the ice hydrometeor species that predominantly grow by vapor deposition, pristine ice, snow, and aggregates (Fig. 9).

The changes in total condensate from DUST MICRO are largely due to the increase in warm rain production (Fig. 12). As dust is ingested by the squall line near cloud base (Fig. 8a), which has been shown to be the dominant source region of aerosol ingestion (Tulet et al., 2010; Seigel and van den Heever, 2012), the nucleation of both cloud and drizzle drops that occurs in association with the small and large dust modes broadens the total size distribution of liquid drops. This helps to speed up the collision-coalescence process that generates rain-sized drops. This can be seen by the up to $50 \%$ increase in the cloud-to-rain conversion rate (henceforth referred to as only cloud-to-rain) just above the gust front (Fig. 12c). The rapid production of rain removes liquid from the squall line that could otherwise help 


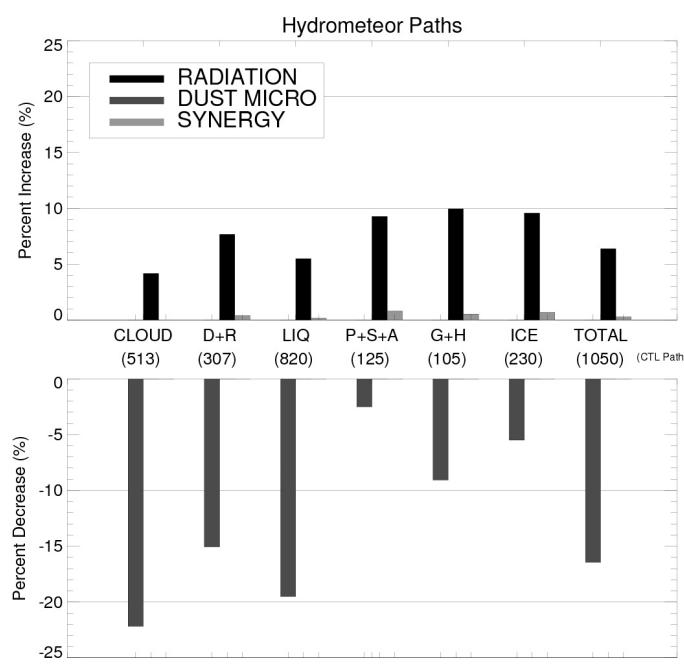

Fig. 9. Horizontally averaged, vertically integrated mixing ratios of various hydrometeors, referred to in the text as hydrometeor paths $\left(\mathrm{g} \mathrm{m}^{-2}\right)$. The hydrometeor paths are expressed as a percent contribution to CONTROL by RADIATION (black bars), DUST MICRO (gray bars), and SYNERGY (light gray bars). D+R is drizzle and rain, $\mathrm{P}+\mathrm{S}+\mathrm{A}$ pristine ice and snow and aggregates, and $\mathrm{G}+\mathrm{H}$ graupel and hail. The numbers below each hydrometeor group are the full field path value for CONTROL.

to increase latent heating higher up in the updraft (notice $50 \%$ reduction in mean total condensate near the freezing level in Fig. 10c), as well as assist in ice formation. SYNERGY also enhances cloud-to-rain near the gust front and is due to the strengthening of the cold pool-forced updraft $(\sim 1-1.5 \mathrm{~km}$ a.g.l. in Fig. $7 \mathrm{c})$ that increases supersaturation, leading to increased nucleation of both large and small dust particles (discussed later) that promotes greater collisioncoalescence (Fig. 12d). Cloud-to-rain also increases for RADIATION (Fig. 12b); however, this is because this squall line (dOffrOn) is stronger (relative to dOffrOff) and has a faster updraft below the freezing level (Fig. 7c), which increases cloud-to-rain due to both enhanced turbulence and increased condensation (discussed later).

The increase in cloud-to-rain for DUST MICRO removes liquid from the squall line that had the potential to be lofted higher into the storm to aid ice formation processes. As such, a reduction in the riming of hail (the species that incurs the most riming) is evident for DUST MICRO (Fig. 13c) in spatial collocation with those regions where significant riming occurs in CONTROL (Fig. 13a). Due to stronger 3$5 \mathrm{~km}$ a.g.l. mid-level updrafts from SYNERGY (Fig. 7c), an increase in the rate of the riming of hail (henceforth referred to as only hail rime) occurs just above the freezing level (Fig. 13d). The change in hail rime for SYNERGY near the freezing level also matches the local changes in total condensate (Fig. 10d), indicating that the riming process is an important contributor to the increase in ice mass (Fig. 9). For
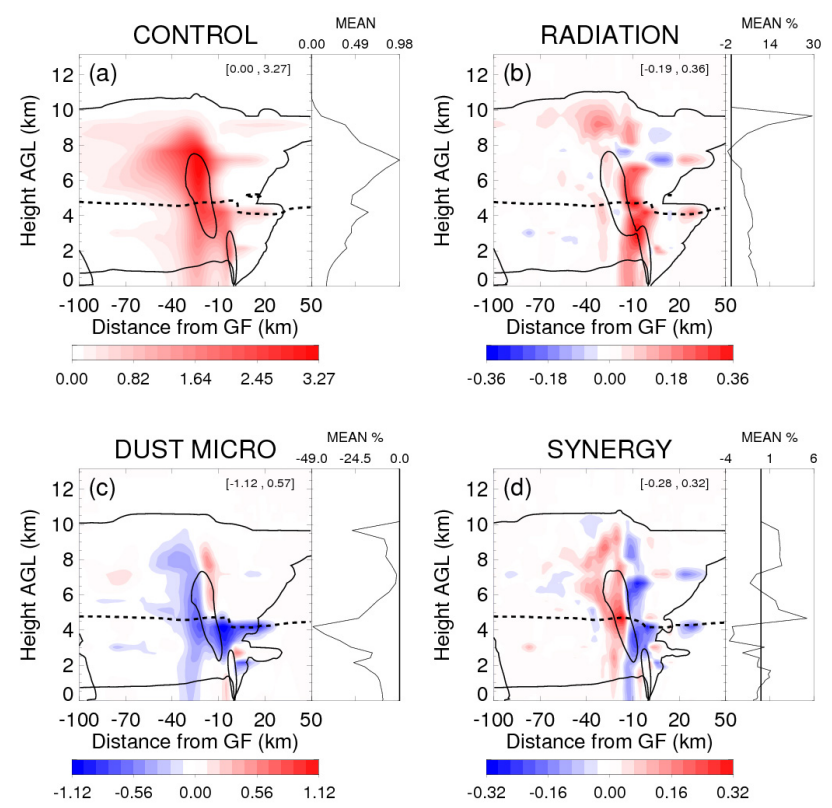

Fig. 10. Meridionally averaged along the gust front and temporally averaged total condensate mixing ratio (total condensate; $\mathrm{g} \mathrm{kg}^{-1}$ ) for (a) CONTROL, (b) RADIATION, (c) DUST MICRO, and (d) SYNERGY from sensitivity simulation hours 1-5. Each vertical cross section is expressed as a horizontal distance from the gust front (x-axis) and a vertical distance a.g.l. (y-axis). Shown on each cross section is the squall line cloud boundary (thick black line; $0.05 \mathrm{~g} \mathrm{~kg}^{-1}$ total condensate), the freezing line (dashed black line), the cold pool boundary (thin black line below $2 \mathrm{~km}$ a.g.1.; -0.05 $\mathrm{m}^{2} \mathrm{~s}^{-2}$ ), the $1 \mathrm{~m} \mathrm{~s}^{-1}$ updraft region (thick black "ovals" stemming from the gust front), and ( $\min , \max$ ) values for total condensate. The cloud boundary, freezing level, cold pool, and updraft contours are of the simulations (a) dOffrOff, (b) dOffrOn, (c) dOnrOff, and (d) dOnrOn. Also shown is a zonally averaged vertical profile that is expressed as a percent contribution relative to CONTROL (line plot) for each factor.

RADIATION, riming is perhaps the most important microphysical process driving a stronger squall line. RADIATION dramatically increases hail rime (Fig. 13b) throughout the depth of the mixed-phase region. This increase in riming is due both to an increase in liquid water (Figs. 9, 10b) and the increase in updraft strength above the freezing level (Fig. 7c), which increases riming rates.

In order to better understand how these changes to the microphysics from the factors alter the vertical distribution of LH, which lead to changes in squall line dynamics (Fovell and Ogura, 1988; Tao et al., 1995; Bryan and Morrison, 2012; Seigel and van den Heever, 2013), a factor separation analysis of the LH budget of the squall line is shown in Fig. 14. RADIATION's contribution to the LH budget of the squall line is clear and matches well with the previous microphysical discussion (Fig. 14b). Radiative cooling near cloud top (Fig. 11) drives destabilization and increased ice supersaturation that helps both to nucleate more ice (ICE 


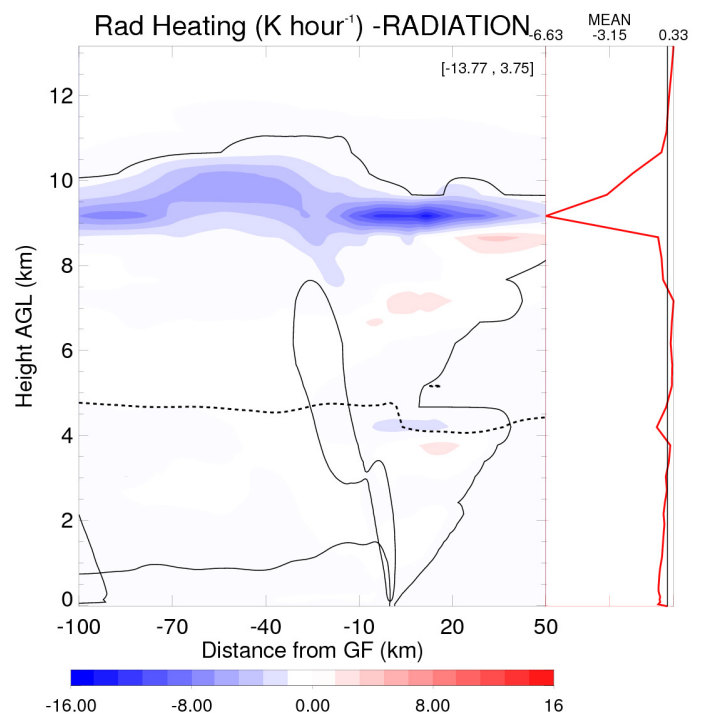

Fig. 11. Same as Fig. 10, except for radiative heating rate $\left(\mathrm{Kh}^{-1}\right)$ and only shown for RADIATION and dOffrOn.

NUC) and grow more ice by vapor deposition (DEP) within the anvil at $\sim 9-11 \mathrm{~km}$ a.g.l. The increase in ice condensate subsequently leads to an increase in melting (MELT), which helps to drive the stronger downdraft (Fig. 7d). This leads to a stronger cold pool (Fig. 5b) and stronger low-level updrafts (Fig. 7c) that increase supersaturation, resulting in a subsequent increase of condensation by up to $41 \%$. The increase in liquid condensate (Fig. 9) forces an increase in the contribution of riming to LH by $13 \%$. All of these microphysical processes act to strengthen the squall line.

Below the freezing level, DUST MICRO highlights the energetic ease of droplet growth versus droplet nucleation. First described by Squires and Twomey (1960), an increase in $\mathrm{CCN}$ assuming constant liquid water content results in a decrease in droplet size but an increase in droplet number, and is also seen here in dOnrOff and dOnrOn relative to dOffrOff and dOffrOn (comparison not shown). As the change in droplet number occurs due to the addition of nucleating aerosol (dust), this increases the droplet surface area. Because the energy barrier to diffuse vapor onto an already present droplet is less than that to nucleate a cloud droplet from a dry aerosol (Prupacher and Klett, 1997), the process of vapor diffusion (COND) takes precedence over droplet nucleation (C+D NUC) on average. This effect has been noted by other aerosol modeling studies of aerosol impacts on deep convection (Storer and van den Heever, 2013; Sheffield et al., 2013) and is also seen for DUST MICRO, whereby the increase in cloud and drizzle nucleation below the freezing level is less than that of vapor diffusion (Fig. 14c). However, the summation of the contribution by these two sources of LH from DUST MICRO, which is maximized below the freezing level, positively contributes to the squall line by $\sim 42 \%$. This agrees well with many AIE studies that show
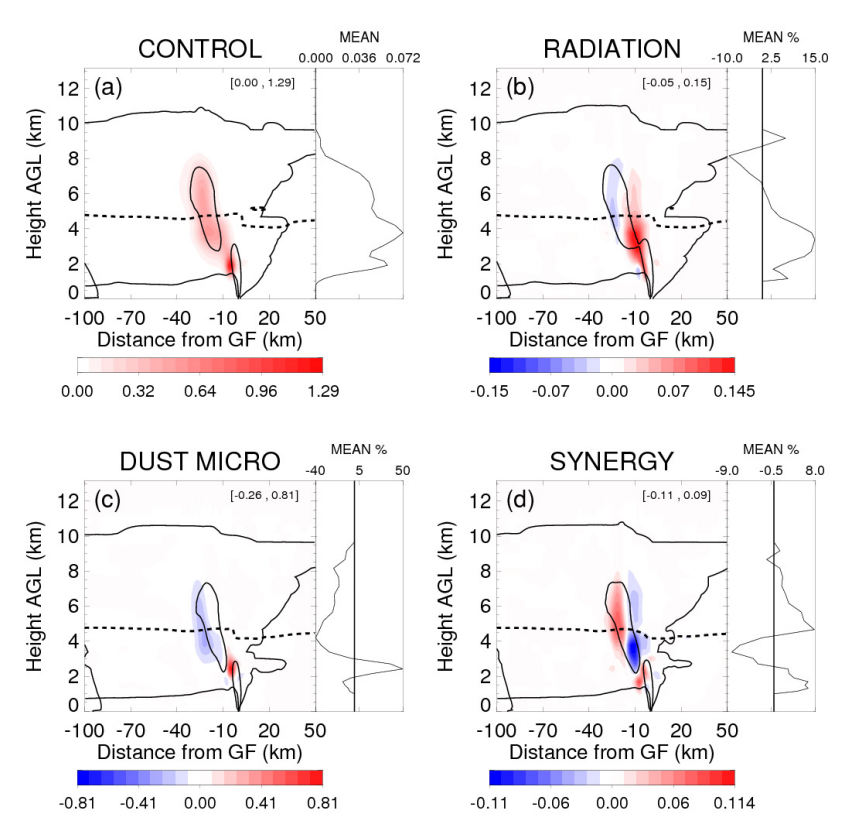

Fig. 12. Same as Fig. 10, except for the collision-coalescence rate $\left(\mathrm{g} \mathrm{kg}^{-1} 5 \mathrm{~min}^{-1}\right)$ between cloud and rain.

increases in $\mathrm{CCN}$ lead to increases in droplet growth due to condensation (Khain et al., 2008; Lee et al., 2008b; Storer and van den Heever, 2013).

Because mineral dust acts as IN, a $37 \%$ increase in ice nucleation is also evident near cloud top; however, DUST MICRO's net contribution to vapor deposition (DEP) is a mere $2.83 \%$. The reason why this contribution is not larger is due to the increase in warm rain (Fig. 11) scouring available water vapor that could have been used to grow ice crystals. The increase in condensation that leads to the invigoration of warm rain precipitation (Fig. 12c) reduces riming by $28 \%$, which has shown to be important for squall line maintenance (Seigel and van den Heever, 2013).

SYNERGY's LH contributions to the squall line helps to explain why it contributes positively to the mid-level organization of the squall line. As the stronger cold poolforced updraft ( $\sim 1-1.5 \mathrm{~km}$ a.g.l. in Fig. $7 \mathrm{c})$ increases supersaturation, it leads to an increase in nucleation near cloud base at $\sim 1.5 \mathrm{~km}$ a.g.l. (Fig. 14d) that slightly enhances the warm-rain process (Fig. 12d). The slight rain increase of up to $10 \%$ in this region (Fig. 10d) leads to the removal of the largest drops that temporarily shuts down the warmrain process higher up $\sim 3 \mathrm{~km}$ a.g.l. (Fig. 12d). Because the precipitating droplets are removed, the surface area to volume ratio increases and promotes greater condensational growth (COND) within the updraft, especially within the 3$5 \mathrm{~km}$ a.g.l. layer. The localized positive contribution to $\mathrm{LH}$ near the freezing level helps to drive a stronger mid-level updraft (Fig. 7c) that positively contributes to CMT (Fig. 7a). The stronger mid-level updraft then leads to a stronger midlevel downdraft (Fig. 7d) that increases melting by up to $6 \%$, 

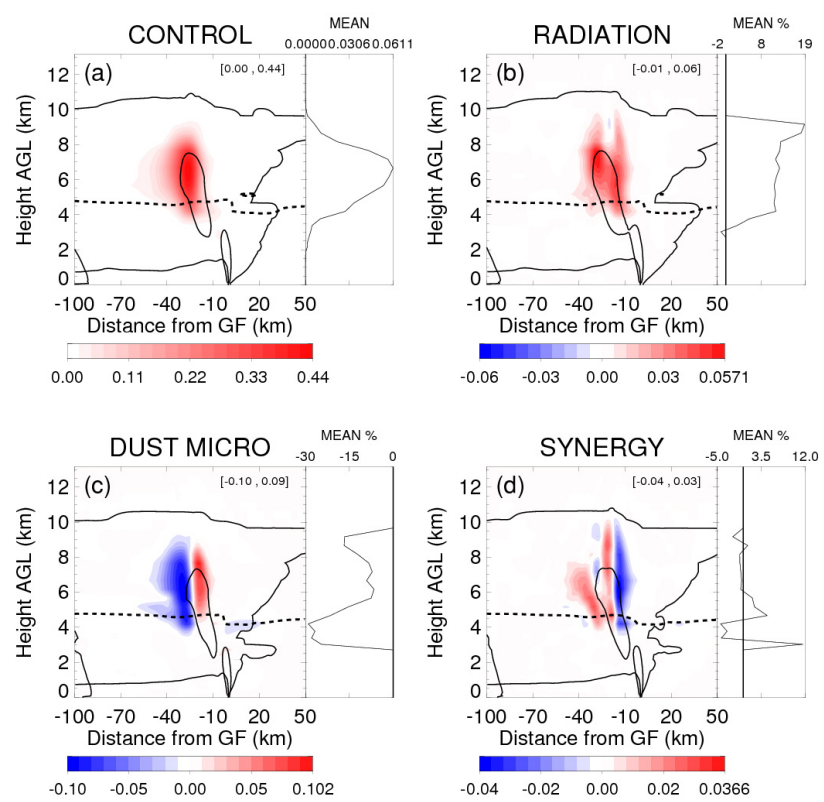

Fig. 13. Same as Fig. 10, except for the riming rate of cloud water onto hail $\left(\mathrm{g} \mathrm{kg}^{-1} 5 \mathrm{~min}^{-1}\right)$.

and further contributes positively to CMT. Seigel and van den Heever (2013) also found that enhanced latent heating near the freezing level helps to invigorate mesoscale organization of squall lines.

\section{Summary}

The goal of this study has been to understand how mineral dust impacts a nocturnal squall line by separating out individual factors that contribute to the aerosol indirect effect. Using the technique of factor separation (Stein and Alpert, 1993), the contributions of radiation (RADIATION), mineral dust acting to alter microphysics (DUST MICRO), and the synergy of dust altering microphysics that leads to changes in radiation (SYNERGY) have been assessed for the squall line. This has been accomplished by using RAMS to simulate an idealized squall line with observed aerosol data from the NAMMA field campaign. Four simulations of the squall line were performed that systematically altered (1) the inclusions of dust acting microphysically (as $\mathrm{CCN}, \mathrm{GCCN}$, and IN) and (2) the inclusion of radiation (Table 2). Factor separation was then used to isolate three factors (RADIATION, DUST MICRO, and SYNERGY; Table 3) from the four simulations that contribute to the squall line. In all experiments the aerosols are not radiatively active, as the focus of this study is to isolate the complex and less understood interactions between mineral dust and cloud microphysics.

The experiments showed that the overall role of mineral dust in the squall line simulated here is to weaken the squall line through changes to precipitation processes. From DUST
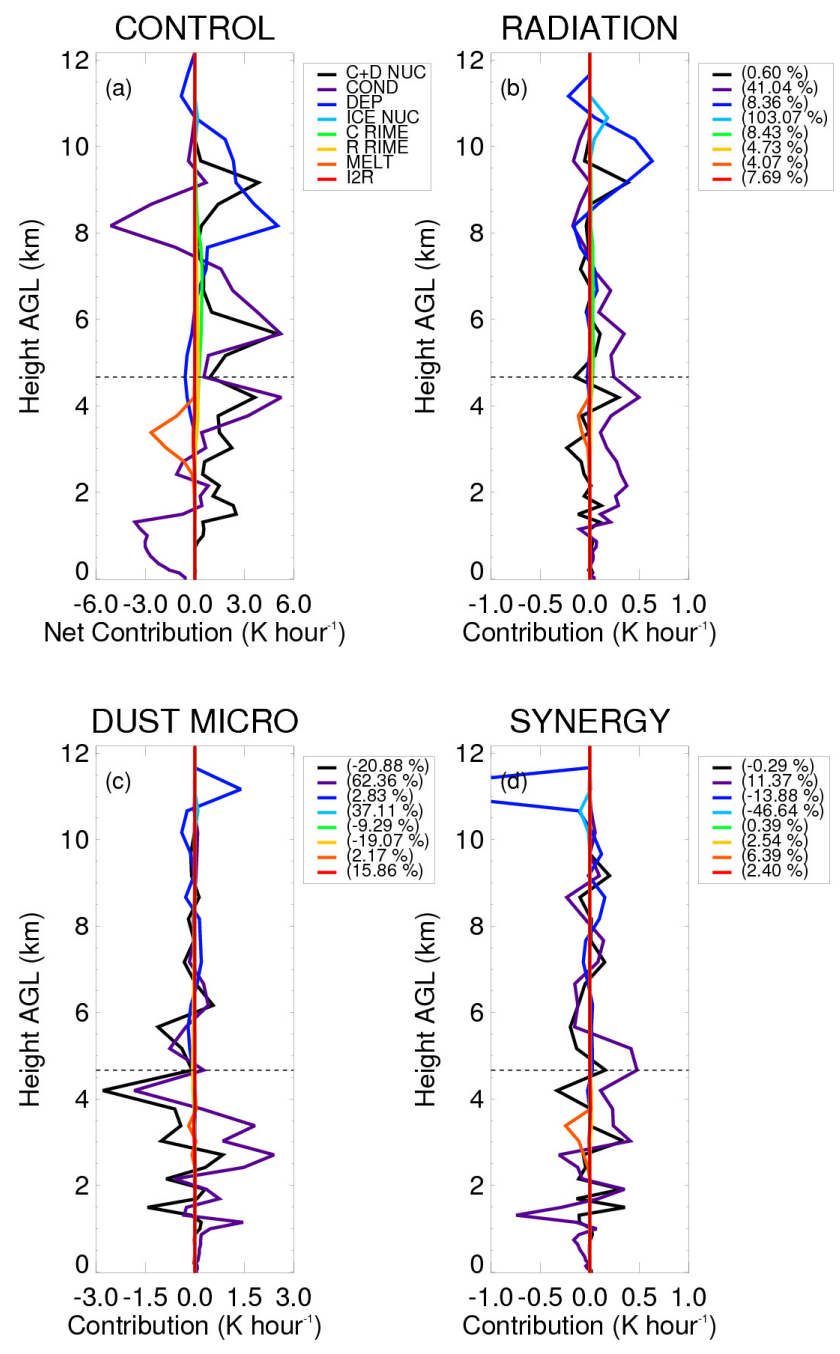

Fig. 14. Cloud-averaged vertical profiles of all microphysical processes that contribute to latent heating $\left(\mathrm{K} \mathrm{h}^{-1}\right)$ for (a) CONTROL, (b) RADIATION, (c) DUST MICRO, and (d) SYNERGY. Cloud is defined by any grid cell that contains at least $0.01 \mathrm{~g} \mathrm{~kg}^{-1}$ of total condensate.

MICRO, it has been shown that, as the mineral dust is ingested into the squall line, it acts as both CCN (mainly small dust mode) and GCCN (mainly large dust mode). The combined influences of $\mathrm{CCN}$ and GCCN act to accelerate the collision-coalescence process. This has been seen by other studies of warm clouds in polluted environments (Feingold et al., 1999; Cheng et al., 2009). The increase in warm rain production near the gust front due to DUST MICRO results in a reduction in supercooled liquid water aloft that reduces the contribution to latent heating by riming by up to $30 \%$. This reduction in ice formation weakens the main updraft of the squall line. The contribution from DUST MICRO to the midlevel portion of the squall line is also to decrease stratiform ice mass and hence weaken the mesoscale downdraft through reduced melting. The combination of weaker updrafts and 
downdrafts from DUST MICRO reduces the convective momentum transport and the overall squall line organization. In association with these processes, the cold pool is weaker, precipitation is reduced, and the total convective mass flux together with net latent heating is suppressed.

In contrast to the microphysical impacts of mineral dust, the role of RADIATION is to invigorate the squall line. This first begins by aiding ice nucleation and ice growth by vapor deposition due to the enhanced cloud top cooling through outgoing longwave radiation. The increase in ice mass due to RADIATION helps to strengthen the mesoscale downdraft of the squall line, which enhances the convective momentum transport, surface cold pool, and precipitation. These all combine to then strengthen the low-level updrafts, which in turn enhance supersaturation that aids condensation and additional latent heat release. This further strengthens the mesoscale organization of the squall line and promotes a positive feedback that is likely initiated from cloud top cooling.

By quantifying the individual contributions to the squall line due to DUST MICRO and RADIATION, it was then possible to assess the SYNERGY contribution to the squall line. SYNERGY represents the non-linear component of the AIE and is the result of the synergistic response to the squall line by having both radiation included and microphysically active dust present. While the overall contribution by SYNERGY to the squall line is small, it is positive for mesoscale organization. This stems from a change to the mid-level microphysical processes of the squall line due to SYNERGY. By having a slightly stronger low-level updraft, additional dust is nucleated by SYNERGY that enhances the warm-rain process just enough to remove the largest rain droplets while still maintaining sufficient droplet surface area to promote extra condensation. The additional latent heating by condensation near the freezing level facilitates a stronger mid-level updraft. This increases melting and results in a stronger mid-level downdraft. The stronger mid-level dynamics promotes better mid-level organization, but is not strong enough to significantly impact precipitation and cold pool intensity. In many studies that utilize factor separation (Romero et al., 1998; Homar et al., 2003; van den Heever et al., 2006), SYNERGY is the dominant term. The fact that SYNERGY is so small in this study emphasizes the importance of aerosols altering precipitation processes within convective systems. The subsequent radiative feedbacks in association with the aerosolinduced changes to the microphysics are thus small.

As the squall line simulated in this study is nocturnal, only the impacts of longwave radiative forcing have been considered. During the day, the presence of shortwave radiation may change the impact of both the mineral dust AIE and radiation on the simulated squall line. Additionally, it is important to note that aerosol impacts on cloud microphysics, such as those investigated herein, are only part of the aerosolcloud interaction problem. Because the aerosol direct effect is a relatively well-known effect, this study deliberately did not allow mineral dust to directly interact with radiation in order to isolate the more complex and less understood problem of aerosol indirect effects. However, to further our understanding of aerosol-cloud interactions, current research is underway to examine the sensitivity of squall lines to mineral dust both during the daytime and when including radiatively active mineral dust.

Acknowledgements. The authors wish to thank the two anonymous reviewers, whose thoughtful comments enhanced the quality of this article. This work was jointly funded by the National Aeronautics and Space Administration under grant NNX07AT11G and the National Science Foundation under grant ATM-0820556.

Edited by: B. Vogel

\section{References}

Adams-Selin, R. D., van den Heever, S. C., and Johnson, R. H.: Impacts of graupel parameterization schemes on idealized bow echo simulations, Mon. Weather Rev., 141, 1241-1262, 2013a.

Adams-Selin, R. D., van den Heever, S. C., and Johnson, R. H.: Sensitivity of bow echo simulation to microphysical parameterizations, Weather Forecast., accepted, 2013b.

Albrecht, B. A.: Aerosols, cloud microphysics, and fractional cloudiness, Science, 245, 1227-1230, 1989.

Alpert, P., Tsidulko, M., and Stein, U.: Can sensitivity studies yield absolute comparisons for the effect of several processes?, J. Atmos. Sci., 52, 597-601, 1995.

Anderson, C. J. and Arritt, R. W.: Mesoscale convective complexes and persistent elongated convective systems over the United States during 1992 and 1993, Mon. Weather Rev., 126, 578-599, 1998.

Andreae, M. O., Rosenfeld, D., Artaxo, P., Costa, A. A., Frank, G. P., Longo, K. M., and Silva-Dias, M. A. F.: Smoking rain clouds over the amazon, Science, 303, 1337, doi:10.1126/science.1092779, 2004.

Bangert, M., Nenes, A., Vogel, B., Vogel, H., Barahona, D., Karydis, V. A., Kumar, P., Kottmeier, C., and Blahak, U.: Saharan dust event impacts on cloud formation and radiation over Western Europe, Atmos. Chem. Phys., 12, 4045-4063, doi:10.5194/acp-124045-2012, 2012.

Benjamin, T. B.: Gravity currents and related phenomena, J. Fluid Mech., 31, 209-248, 1968.

Berg, W., L'Ecuyer, T., and van den Heever, S. C.: Evidence for the impact of aerosols on the onset and microphysical properties of rainfall from a combination of satellite observations and cloudresolving model simulations, J. Geophys. Res, 113, D14S23, doi:10.1029/2007JD009649, 2008.

Borys, R. D., Lowenthal, D. H., Wetzel, M. A., Herrera, F., Gonzalez, A., and Harris, J.: Chemical and microphysical properties of marine stratiform cloud in the North Atlantic, J. Geophys. Res., 103, 22073-22085, 1998.

Bryan, G. H. and Morrison, H.: Sensitivity of a simulated squall line to horizontal resolution and parameterization of microphysics, Mon. Weather Rev., 140, 202-225, doi:10.1175/MWR-D-11$00046.1,2012$. 
Bryan, G. H., Knievel, J. C., and Parker, M. D.: A multimodel assessment of RKW theory's relevance to squall-line characteristics, Mon. Weather Rev., 134, 2772-2792, 2006.

Bryan, G. H., Rotunno, R., and Fritsch, J. M.: Roll circulations in the convective region of a simulated squall line, J. Atmos. Sci., 64, 1249-1266, 2007.

Carrio, G. G., van den Heever, S. C., and Cotton, W. R.: Impacts of nucleating aerosol on anvil-cirrus clouds: A modeling study, Atmos. Res., 84, 111-131, 2007.

Chen, S. and Cotton, W. R.: The sensitivity of a simulated extratropical mesoscale convective system to longwave radiation and ice-phase microphysics, J. Atmos. Sci., 45, 3897-3910, 1988.

Cheng, W. Y. Y., Carrio, G. G., Cotton, W. R., and Saleeby, S. M.: Influence of cloud condensation and giant cloud condensation nuclei on the development of precipitating trade wind cumuli in a large eddy simulation, J. Geophys. Res., 114, D08201, doi:10.1029/2008JD011011, 2009.

Chin, H.-N. S.: The impact of the ice phase and radiation on a midlatitude squall line system, J. Atmos. Sci., 51, 3320-3343, 1994.

Churchill, D. D. and Houze Jr., R. A.: Effects of radiation and turbulence on the diabatic heating and water budget of the stratiform region of a tropical cloud cluster, J. Atmos. Sci., 48, 903-922, 1991.

Cotton, W. R., Pielke Sr., R. A., Walko, R. L., Liston, G. E., Tremback, C. J., Jiang, H., McAnelly, R. L., Harrington, J. Y., Nicholls, M. E., Carrio, G. G., and McFadden, J. P.: RAMS 2001: Current status and future directions. Meteorol. Atmos. Phys., 82, 5-29, 2003.

de Boer, G., Hashino, T., and Tripoli, G. J.: Ice nucleation through immersion freezing in mixed-phase stratiform clouds: Theory and numerical simulations, Atmos. Res., 96, 315-324, 2010.

DeMott, P. J., Prenni A. J., Lui, X., Kreidenweis, S. M., Petters, M. D., Twohy, C. H., Richardson, M. S., Eidhammer, T., and Rogers, D. C.: Predicting global atmospheric ice nuclei distributions and their impacts on climate, P. Natl. Acad. Sci., 107, 11217-11222, doi:10.1073/pnas.0910818107, 2010.

Dharssi, I., Kershaw, R., and Tao, W. K.: Sensitivity of a simulated tropical squall line to long-wave radiation, Q. J. Roy. Meteorol. Soc., 123, 187-206, 1997.

Dudhia, J.: Numerical study of convection observed during the Winter Monsoon Experiment using a mesoscale two-dimensional model, J. Atmos. Sci., 46, 586-601, 1989.

Feingold, G. and Heymsfield, A. J.: Parameterizations of condensational growth of droplets for use in general circulation models, J. Atmos. Sci., 49, 2325-2342, 1992.

Feingold, G., Tzivion, S., and Levin, Z.: Evolution of raindrop spectra. Part I: Solution to the stochastic collection/breakup equation using the method of moments, J. Atmos. Sci., 45, 3387-3399, 1988.

Feingold, G., Walko, R. L., Stevens, B., and Cotton, W. R.: Simulations of marine stratocumulus using a new microphysical parameterization scheme, Atmos. Res., 47-48, 505-528, 1998.

Feingold, G., Cotton, W. R., Kreidenweis, S. M., and Davis, J. T.: The impact of giant cloud condensation nuclei on drizzle formation in stratocumulus: Implications for cloud radiative properties, J. Atmos. Sci., 56, 4100-4117, 1999.

Ferek, R. J., Garrett, T., Hobbs, P. V., Strader, S., Johnson, D., Taylor, J. P., Nielson, K., Ackerman, A. S., Kogan, Y., Liu, Q., Albrecht, B. A., and Babb, D.: Drizzle suppression in ship tracks,
J. Atmos. Sci., 57, 2707-2728, 2000.

Fierro, A. O., Leslie, L. M., Mansell, E. R., and Straka, J. M.: Numerical simulations of the microphysics and electrification of the weakly electrified 9 February 1993 TOGA COARE squall line: comparisons with observations, Mon. Weather Rev., 136, 364379, 2008.

Flatau, P. J., Tripoli, G. J., Verlinde, J., and Cotton, W. R.: The CSURAMS Cloud Microphysical Module: General Theory and Code Documentation, Dept. of Atmos. Sci., Colorado State Univ., Fort Collins, CO 80523, Atmos. Sci. Pap., 451, 88 pp., 1989.

Forster, P., Artaxo, P., Bernsten, T., Betts, R., Fahey, D. W., Haywood, J., Lean, J., Lowe, D. C., Myhre, G., Nganga, J., Prinn, R., Raga, G., Schulz, M., and Van Dorland, R.: Changes in atmospheric constituents and in radiative forcing, in Climate Change 2007: The Physical Science Basis - Contribution of Working Group I to the Fourth Assessment Report of the Intergovernmental Panel on Climate Change, edited by: Solomon, S., Qin, D., Manning, M., Chen, Z., Marquis, M., Averyt, K. B., Tignor, M., and Miller, H. L., 129-234, Cambridge Univ. Press, Cambridge, UK, 2007.

Fovell, R. G. and Ogura, Y.: Numerical simulation of a midlatitude squall line in two dimensions, J. Atmos. Sci., 45, 3846-3879, 1988.

Frame, J. and Markowski, P.: The interaction of simulated squall lines with idealized mountain ridges, Mon. Weather Rev., 134, 1919-1941, 2006.

Harrington, J. Y.: The effects of radiative and microphysical processes on simulated warm and transition season Arctic stratus. Ph.D. dissertation, Atmospheric Science Paper 637, Department of Atmospheric Science, Colorado State University, 289 pp., 1997.

Heymsfield, A. J. and McFarquhar, G. M.: Microphysics of INDOEX clean and polluted trade cumulus clouds, J. Geophys. Res., 106, 28653-28673, 2001.

Heymsfield, A. J. and Sabin, R. M.: Cirrus crystal nucleation by homogeneous freezing of solution drops, J. Atmos. Sci., 46, 22522264, 1989.

Hill, G. E.: Factors controlling the size and spacing of cumulus clouds as revealed by numerical experiments, J. Atmos. Sci., 31, 646-673, 1974.

Homar, V., Romero, R., Stensrud, D. J., Ramis, C., and Alonso, S.: Numerical diagnosis of a small, quasi-tropical cyclone over the western Mediterranean: dynamical vs. boundary factors, Q. J. Roy. Meteorol. Soc., 129, 1469-1490, 2003.

Houze Jr., R. A.: Cloud Dynamics. Academic Press, 573 pp., 1993. Igel, A. L., van den Heever, S. C., Naud, C. M., Saleeby, S. M., and Posselt, D. J.: Sensitivity of warm frontal processes to cloudnucleating aerosol concentrations, J. Atmos. Sci., in press, 2013.

IPCC: "Climate change 2001: the scientific basis", Intergovernmental Panel on Climate Change, http://www.grida.no/climate/ ipcc_tar/wg1/index.htm, 2001.

Ismail, S., Ferrare, R. A., Browell, E. V., Kooi, S. A., Dunion, J. P., Heymsfield, G., Notari, A., Butler, C. F., Burton, S., Fenn, M., Krishnamurti, T. N., Biswas, M. K., Chen, G., and Anderson, B.: LASE measurements of water vapor, aerosol, and cloud distributions in Saharan Air Layers and tropical disturbances, J. Atmos. Sci., 67, 1026-1047, 2010.

Jirak, I. L., Cotton, W. R., and McAnelly, R. L.: Satellite and radar survey of mesoscale convective system development, Mon. 
Weather Rev., 131, 2428-2449, 2003.

Kaufman, Y. J. and Nakajima, T.: Effect of Amazon smoke on cloud microphysics and albedo - Analysis from satellite imagery, J. Appl. Meteor., 32, 729-744, 1993.

Khain, A. P., Ovtchinnikov, M., Pinsky, M., Pokrovsky, A., and Krugliak, H.: Notes on the state-of-the-art numerical modeling of cloud microphysics, Atmos. Res., 55, 159-224, 2000.

Khain, A. P., Rosenfeld, D., and Pokrovsky, A.: Aerosol impact on the dynamics and microphysics of deep convective clouds, Q. J. Roy. Meteor. Soc., 131, 2639-2663, 2005.

Khain, A. P., BenMoshe, N., and Pokrovsky, A.: Factors determining the impact of aerosols on surface precipitation from clouds: An attempt at classification, J. Atmos. Sci., 65, 1721-1748, 2008.

Klemp, J. B. and Wilhelmson, R. B.: The simulation of threedimensional convective storm dynamics, J. Atmos. Sci., 35, 1070-1096, 1978.

Laing, A. G. and Fritsch, J. M.: The global population of mesoscale convective complexes, Q. J. Roy. Meteorol. Soc., 123, 389-405, 1997.

Lane, P. T. and Moncrieff, M. W.: Characterization of momentum transport associated with organized moist convection and gravity waves, J. Atmos. Sci., 67, 3208-3225, 2010.

Lee, S. S., Donner, L., and Phillips, V.: Examination of aerosol effects on precipitation in deep convective clouds during the 1997 ARM summer experiment, Q. J. Roy. Meteorol. Soc., 134, 12011220, 2008a.

Lee, S. S., Donner, L., Phillips, V., and Ming, Y.: The dependence of aerosol effects on clouds and precipitation on cloud-system organization, shear and stability, J. Geophys. Res., 113, D16202, doi:10.1029/2007JD009224, 2008b.

Lee, S. S., Donner, L. J., and Phillips, V. T. J.: Impacts of aerosol chemical composition on microphysics and precipitation in deep convection, Atmos. Res., 94, 220-237, doi:10.1016/j.atmosres.2009.05.015, 2009.

Li, G., Wang, Y., Lee, K.-H., Diao, Y., and Zhang, R.: The impacts of aerosols on development and precipitation of a mesoscale squall line, J. Geophys. Res., 114, D17205, doi:10.1029/2008JD011581, 2009.

Lilly D. K.: On the numerical simulation of buoyant convection, Tellus, XIV, 148-172, 1962.

Lynn, B. H., Khain, A., Dudhia, J., Rosenfeld, D., Pokrovsky, A., and Seifert, A.: Spectral (bin) microphysics coupled with a mesoscale model (MM5): Part I. Model description and first results, Mon. Weather Rev., 133, 44-58, doi:10.1175/MWR2840.1, 2005a.

Lynn, B. H., Khain, A., Dudhia, J., Rosenfeld, D., Pokrovsky, A., and Seifert, A.: Spectral (bin) microphysics coupled with a mesoscale model (MM5): Part II. Simulation of a CaPE rain event with a squall line, Mon. Weather Rev., 133, 59-71, doi:10.1175/MWR-2841.1, 2005b.

Masson, V., Champeaux, J.-L., Chauvin, F., Meriguet, C., and Lacaze, R.: A global database of land surface parameters at 1-km resolution in meteorological and climate models, J. Climate, 16, 1261-1282, 2003.

Matrosov, S. Y.: Retrieval of vertical pro?les of ice cloud microphysics from radar and IR measurements using tuned regressions between re?ectivity and cloud parameters, J. Geophys. Res., 104, 16741-16753, 1999.
Matsui, T., Masunaga, H., Pielke Sr., R. A., and Tao, W.-K.: Impact of aerosols and atmospheric thermodynamics on cloud properties within the climate system, Geophys. Res. Lett., 31, L06109, doi:10.1029/2003GL019287, 2004.

Meyers, M. P., Walko, R. L, Harrington, J. Y., and Cotton, W. R.: New RAMS cloud microphysics parameterization. Part II: The two-moment scheme, Atmos. Res., 45, 3-39, 1997.

Morrison, H.: On the robustness of aerosol effects on an idealized supercell storm simulated with a cloud system-resolving model, Atmos. Chem. Phys., 12, 7689-7705, doi:10.5194/acp-12-76892012, 2012.

Morrison, H. and Grabowski, W. W.: Comparison of bulk and bin warm-rain microphysics models using a kinematic framework, J. Atmos. Sci., 64, 2839-2861, 2007.

Morrison, H., Thompson, G., and Tatarskii, V.: Impact of cloud microphysics on the development of trailing stratiform precipitation in a simulated squall line: Comparison of one- and two-moment schemes, Mon. Weather Rev., 137, 991-1007, 2009.

Morrison, H., Tessendorf, S., Ikeda, K., and Thompson, G.: Sensitivity of a simulated mid-latitude squall line to parameterization of raindrop breakup, Mon. Weather Rev., 140, 2437-2460, doi:10.1175/MWR-D-11-00283.1, 2012.

Nesbitt, S. W., Cifelli, R., and Rutledge, S. A.: Storm morphology and rainfall characteristics of TRMM precipitation features, Mon. Weather Rev., 134, 2702-2721, doi:10.1175/MWR3200.1, 2006.

Parker, M. D. and Johnson, R. H.: Organizational modes of midlatitude mesoscale convective systems. Mon. Weather Rev., 128, 3413-3436, 2000.

Perry, K., Cahill, T., Eldred, R., Dutcher, D. D., and Gill, T. E.: Long-range transport of North African dust to the east- ern United States, J. Geophys. Res., 102, 11225-11238, 1997.

Pielke, R. A., Cotton, W. R., Walko, R. L., Tremback, C. J., Lyons, W. A., Grasso, L. D., Nicholls, M. E., Moran, M. D., Wesley, D. A., Lee, T. J., and Copeland, J. H.: A comprehensive meteorological modeling system - RAMS, Meteor. Atmos. Phys., 49, 69-91, 1992.

Prospero, J. M.: Saharan dust transport over the North Atlantic Ocean and Mediterranean: An overview. The Impact of Desert Dust Across the Mediterranean, edited by: Guerzoni, S. and Chester, R., Kluwer Academic, 133-151, 1996.

Prospero, J. M.: Long-term measurements of the transport of African mineral dust to the southeastern United States: Implications for regional air quality. J. Geophys. Res., 104, 1591715927, 1999.

Pruppacher, H. R. and Klett, J. D.: Microphysics of Clouds and Precipitation, 2d ed. Kluwer Academic, 954 pp., 1997.

Romero, R., Ramis, C., Alonso, S., Doswell III, C. A., and Stensrud, D. J.: Mesoscale model simulations of three heavy precipitation events in the western Mediterranean region, Mon. Weather Rev., 126, 1859-1881, 1998.

Rosenfeld, D.: Suppression of rain and snow by urban and industrial air pollution, Science, 287, 1793-1796, doi:10.1126/science.287.5459.1793, 2000.

Rosenfeld, D. and Feingold, G.: Explanation of the discrepancies among satellite observations of the aerosol indirect effects, Geophys. Res. Lett., 30, 1776, doi:10.1029/2003GL017684, 2003.

Rosenfeld, D., Lohmann, U., Raga, G., O’Dowd, C., Kulmala, M., Fuzzi, S., Reissell, A., and Andreae, M.: Flood or drought: 
how do aerosols a_ect precipitation? Science, 321, 1309, doi:10.1126/science.1160606, 2008.

Rotunno, R., Klemp, J. B., and Weisman, M. L.: A theory for strong, long-lived squall lines, J. Atmos. Sci., 45, 463-485, 1988.

Rotunno, R., Klemp, J. B., and Weisman, M. L.: Comments on "A numerical investigation of the organization and interaction of the convective and tratiform regions of tropical squall lines", J. Atmos. Sci, 47, 1031-1033, 1990.

Saleeby, S. M. and Cotton, W. R.: A large-droplet mode and prognostic number concentration of cloud droplets in the Colorado State University Regional Atmospheric Modeling System (RAMS). Part I: Module descriptions and supercell test simulations, J. Appl. Meteor., 43, 182-195, 2004.

Saleeby, S. M. and van den Heever, S. C.: Developments in the CSU-RAMS aerosol model: Emissions, nucleation, regeneration, deposition, and radiation, J. Appl. Meteorol. Clim., accepted, 2013.

Sassen, K., DeMott, P. J., Prospero, J. M., and Poellet, M. R.: Saharan dust storms and indirect aerosol effects on clouds: CRYSTAL-FACE results, Geophys. Res. Lett., 30, 1633, doi:10.1029/2003GL017371, 2003.

Seifert, A. and Beheng, K. D.: A two-moment cloud microphysics parameterization for mixed-phase clouds. Part 2: Maritime vs. continental deep convective storms, Meteorol. Atmos. Phys., 92, 67-82, 2006.

Seigel, R. B. and van den Heever, S. C.: Dust lofting and ingestion by supercell storms, J. Atmos. Sci., 69, 1453-1473, 2012.

Seigel, R. B. and van den Heever, S. C.: Squall line intensification via hydrometeor recirculation, J. Atmos. Sci., in press, 2013.

Sheffield, Amanda M., van den Heever, S. C., and Saleeby, S. M. Saleeby: Growth of cumulus congestus clouds when impacted by aerosols, J. Atmos. Sci., accepted, 2013.

Smagorinsky, J.: General circulation experiments with the primitive equations. I. The basic experiment, Mon. Weather Rev., 91, 99164, 1963.

Smull, B. F. and Houze, Jr., R. A.: Rear inflow in squall lines with trailing-stratiform precipitation, Mon. Weather Rev., 115, 28692889, 1987.

Solomos, S., Kallos, G., Kushta, J., Astitha, M., Tremback, C., Nenes, A., and Levin, Z.: An integrated modeling study on the effects of mineral dust and sea salt particles on clouds and precipitation, Atmos. Chem. Phys., 11, 873-892, doi:10.5194/acp11-873-2011, 2011.

Squires, P. and Twomey, S.: The relation between cloud drop spectra and the spectrum of cloud nuclei, in: Physics of Precipitation, Geophys. Monogr. Ser., vol. 5, edited by: Weickmann, H., 211219, AGU, Washington, DC, 1960.

Stein, U. and Alpert, P.: Factor separation in numerical simulations, J. Atmos. Sci., 50, 2107-2115, 1993.

Storer, R. L. and van den Heever, S. C.: Microphysical processes evident in aerosol forcing of tropical deep convection, J. Atmos. Sci., 67, 430-446, 2013.

Storer, R. L., van den Heever, S. C., and Stephens, G. L.: Modeling aerosol impacts on convective storms in different environments, J. Atmos. Sci., 67, 3904-3915, 2010.

Tao, W., Simpson, J. and Soong, S: Numerical simulation of a subtropical squall line over the Taiwan Strait, Mon. Weather Rev., 119, 2699-2723, 1991.
Tao, W., Simpson, J., Sui, C., Ferrier, B., Lang, S., Scala, J., Chou, M., and Pickering, K.: Heating, moisture and water budgets of tropical and mid-latitude squall lines: comparison and sensitivity to long-wave radiation, J. Atmos. Sci., 50, 673-890, 1993.

Tao, W., Scala, J. R., Ferrier, B., and Simpson, J.: The effect of melting processes on the development of a tropical and a midlatitude squall line, J. Atmos. Sci., 52, 1934-1948, 1995.

Tao, W., Chen, J.-P., Li, Z., Wang, C., and Zhang, C.: Impacts of aerosols on convective clouds and precipitation, Rev. Geophys., 50, RG2001, doi:10.1029/2011RG000369, 2012.

Tegen, I. and Fung, I.: Modeling of mineral dust in the atmosphere: Sources, transport and optical thickness, J. Geophys. Res., 99, 22897-22914, 1994.

Thorpe, A. J., Miller, M. J., and Moncrieff, M. W.: Two-dimensional convection in non-constant shear: A model of midlatitude squall lines, Q. J. Roy. Meteor. Soc., 108, 739-762, 1982.

Tompkins, A. M.: Organization of tropical convection in low vertical wind shears: The role of cold pools, J. Atmos. Sci., 58, 1650 1672, 2001.

Trier, S. B., Skamarock, W. C., and LeMone, M. A.: Structure and evolution of the 22 February 1993 TOGA COARE squall line: Organization mechanisms inferred from numerical simulations, J. Atmos. Sci., 54, 386-407, 1997.

Tulet, P., Crahan-Kaku, K., Leriche, M., Aouizerats, B., and Crumeyrolle, S.: Mixing of dust aerosols into a mesoscale convective system: generation, filtering and possible feedbacks on ice anvils, Atmos. Res., 96, 302-314, 2010.

Twohy, C. H., Kreidenweis, S. M., Eidhammer, T., Browell, E. V., Heymsfield, A. J., Bansemer, A. R., Anderson, B. E., Chen, G., Ismail, S., DeMott, P. J., and van den Heever, S. C.: Saharan dust particles nucleate droplets in eastern Atlantic clouds, Geophys. Res. Lett., 36, L01807, doi:10.1029/2008GL035846, 2009.

Twomey, S.: The influence of pollution on the shortwave albedo of clouds, J. Atmos. Sci., 34, 1149-1152, 1977.

van den Heever, S. C. and Cotton, W. R.: The impact of hail size on simulated supercell storms, J. Atmos. Sci., 61, 1596-1609, 2004.

van den Heever, S. C. and Cotton, W. R.: Urban aerosol impacts n downwind convective storms, J. Appl. Meteorol. Climatol., 46, 828-850, doi:10.1175/JAM2492.1, 2007.

van den Heever, S. C., Carrió, G. G., Cotton, W. R., DeMott, P. J., and Prenni, A. J.: Impacts of nucleating aerosol on Florida storms. Part I: Mesoscale simulations, J. Atmos. Sci., 63, 1752 1775, 2006.

van den Heever, S. C., Stephens, G. L., and Wood, N. B.: Aerosol indirect effects on tropical convection characteristics under conditions of radiative-convective equilibrium, J. Atmos. Sci., 68, 699-718, doi:10.1175/2010JAS3603.1, 2011.

Van Weverberg, K., Vogelmann, A., Morrison, H., and Milbrandt, J.: Sensitivity of Idealized Squall Line Simulations to the Level of Complexity Used in Two-Moment Bulk Microphysics Schemes, Mon. Weather Rev., 140, 1883-1907, 2012.

Verlinde, J., Flatau, P. J., and Cotton, W. R.: Analytical solutions to the collection growth equation: Comparison with approximate methods and application to cloud microphysics parameterization schemes, J. Atmos. Sci., 47, 2871-2880, 1990.

Walko, R. L., Tremback, C. J., Pielke, R. A., and Cotton, W. R.: An interactive nesting algorithm for stretched grids and variable nesting ratios, J. Appl. Meteol., 34, 994-999, 1995. 
Wang, C.: A model study of the response of tropical deep convection to the increase of CCN concentration: 1. Dynamics and microphysics, J. Geophys. Res., 110, D21211, doi:10.1029/2004JD005720, 2005.

Weisman, M. L.: The role of convectively generated rear-inflow jets in the evolution of long-lived mesoconvective systems, J. Atmos. Sci., 49, 1826-1847, 1992.

Weisman, M. L.: The genesis of severe, long-lived bow echoes, J. Atmos. Sci., 50, 645-670, 1993.

Weisman, M. L. and Klemp, J. B.: The dependence of numerically simulated convective storms on vertical wind shear and buoyancy, Mon. Weather Rev., 110, 504-520, 1982.
Weisman, M. L. and Rotunno, R.: "A theory for strong long-lived squall lines" revisited, J. Atmos. Sci., 61, 361-382, 2004.

Weisman, M. L. and Rotunno, R.: Reply, J. Atmos. Sci., 62, $2997-$ 3002, 2005.

Weisman, M. L., Klemp, J. B., and Rotunno, R.: Structure and evolution of numerically simulated squall lines, J. Atmos. Sci., 45, 1990-2013, 1988.

Zipser, E. J., and 22 coauthors: The Saharan air layer and the fate of African easterly waves: NASA's AMMA 2006 field program to study tropical cyclogenesis: NAMMA, B. Am. Meteorol. Soc., 90, 1137-1156, doi:10.1175/2009BAMS2728.1, 2009. 